\title{
Climatology and Forcing of the Quasi-Biennial Oscillation in the MAECHAM5 Model
}

\author{
M. A. Giorgetta \\ Max Planck Institute for Meteorology, Hamburg, Germany \\ E. MANZINI \\ National Institute for Geophysics and Volcanology, Bologna, Italy \\ E. ROECKNER AND M. ESCH \\ Max Planck Institute for Meteorology, Hamburg, Germany

\section{BENGTSSON} \\ Max Planck Institute for Meteorology, Hamburg, Germany, and Environmental Systems Science Centre, University of Reading, \\ Reading, United Kingdom
}

(Manuscript received 23 January 2005, in final form 21 June 2005)

\begin{abstract}
The quasi-biennial oscillation $(\mathrm{QBO})$ in the equatorial zonal wind is an outstanding phenomenon of the atmosphere. The QBO is driven by a broad spectrum of waves excited in the tropical troposphere and modulates transport and mixing of chemical compounds in the whole middle atmosphere. Therefore, the simulation of the QBO in general circulation models and chemistry climate models is an important issue. Here, aspects of the climatology and forcing of a spontaneously occurring QBO in a middle-atmosphere model are evaluated, and its influence on the climate and variability of the tropical middle atmosphere is investigated. Westerly and easterly phases are considered separately, and 40-yr ECMWF Re-Analysis (ERA-40) data are used as a reference where appropriate. It is found that the simulated QBO is realistic in many details. Resolved large-scale waves are particularly important for the westerly phase, while parameterized gravity wave drag is more important for the easterly phase. Advective zonal wind tendencies are important for asymmetries between westerly and easterly phases, as found for the suppression of the easterly phase downward propagation. The simulation of the QBO improves the tropical upwelling and the atmospheric tape recorder compared to a model without a QBO. The semiannual oscillation is simulated realistically only if the QBO is represented. In sensitivity tests, it is found that the simulated QBO is strongly sensitive to changes in the gravity wave sources. The sensitivity to the tested range of horizontal resolutions is small. The stratospheric vertical resolution must be better than $1 \mathrm{~km}$ to simulate a realistic QBO.
\end{abstract}

\section{Introduction}

The general circulation of the atmosphere exhibits various modes of variability, each with its characteristic domain and scales. Within the equatorial stratosphere, the quasi-biennial oscillation (QBO) in the zonal wind explains the largest fraction of the circulation variability because of its outstanding structure in space and

Corresponding author address: Marco A. Giorgetta, Max Planck Institute for Meteorology, Bundesstrasse 53, 20146 Hamburg, Germany.

E-mail: marco.giorgetta@zmaw.de time. Furthermore, the QBO plays an important role in the interpretation of observed variations in the distribution of ozone and other chemical species in the whole stratosphere (see Baldwin et al. 2001 for a general review). It is therefore very desirable to have general circulation models (GCMs) and chemistry climate models able to simulate the QBO in some detail.

However, modeling the QBO in GCMs is still a challenge. So far, only a few simulations of oscillations in the zonal wind in the equatorial stratosphere have been presented. In particular, some of these oscillations have realistic time scales and resemble the observed QBO (Takahashi 1999; Scaife et al. 2000; Giorgetta et al. 
2002), while others are characterized by periods deviating significantly from the observed one, and are typically faster (Takahashi1996; Hamilton et al. 1999). The difficulties to simulate the QBO have various reasons, in part discussed previously (e.g., Giorgetta et al. 2002). In any case, such difficulties are indicative of serious biases in the representation of the wave-mean-flow interaction, which is the key process in the QBO forcing (Holton and Lindzen 1972). The wave-mean-flow interaction consists of the vertical propagation of an equatorial wave spectrum of tropospheric origin and its dissipation by dynamical and physical mechanisms. In a numerical simulation, these flow-dependent processes must be represented on all relevant scales.

In historic perspective, the first theory (Lindzen and Holton 1968) proposed that gravity waves, which are not resolved in GCMs, provide the required eastward and westward momentum fluxes. The revised theory (Holton and Lindzen 1972) kept the original mechanism, but proposed instead large-scale Kelvin and Rossby gravity waves to provide the required momentum fluxes. These waves are horizontally well resolved in most GCMs so that it was expected that middleatmosphere GCMs could simulate the QBO, provided that the vertical resolution is improved such that the vertical structures of these waves are well resolved. Only later it became clear that large-scale waves are not sufficient to explain the QBO (Takahashi and Boville 1992) and that gravity waves must play an important role (Dunkerton 1997). Currently, it is assumed that a broad spectrum must be considered. In terms of modeling the QBO in GCMs, this meant that the wavemean-flow interaction must be simulated explicitly for the resolved spectrum of waves and implicitly by a parameterization for the unresolved scales relevant for the QBO simulation.

For the resolved scales, sufficient vertical resolution is a necessary condition, which has however become less restrictive than in the past due to increased computing power. The key problem is the simulation of tropical convection, which must excite the resolved wave spectrum. Differences in the temporal characteristic of modeled convection can be substantial, as shown by Horinouchi et al. (2003), which can be attributed partly to the characteristics of the different parameterizations of convection (Ricciardulli and Garcia 2000). Wave excitation from a particular parameterization can be highly sensitive to the choice of the internal parameters and may occur also as a result of resolved convective overturning if the parameterized overturning does not remove the instabilities efficiently enough, as demonstrated by Scinocca and McFarlane (2004). Additionally, it should be noted that parameterized convection depends not only on the implemented scheme but indirectly also on other processes that determine conditions for the occurrence of convection. Therefore, simulating the QBO is not only a test for the wave propagation and dissipation in the stratosphere, but also of tropospheric processes and the resulting representation of tropical weather and climate.

The purpose of the current work is to evaluate a number of aspects of the climatology and the forcing of the QBO as simulated by the high vertical resolution configuration of the MAECHAM5 model. While the ability of the MAECHAM5 model to simulate a realistic QBO in zonal winds has been demonstrated in Giorgetta et al. (2002), the current work focuses on a separate analysis of westerly and easterly phases of the QBO by means of phase composites with respect to the onset time at the equator at $20 \mathrm{hPa}$. This composite technique is used also to isolate the related temperature signal and the forcing characteristic for each phase. Furthermore, this work focuses on the simulation of QBO effects on the climate and variability of the tropical stratosphere as found in the tropical upwelling, in the atmospheric tape recorder signal in water vapor anomalies, and in the semiannual oscillation (SAO). Finally, the issue of sensitivity of the QBO simulation to the model configuration is addressed. The 40-yr European Centre for Medium-Range Weather Forecasts (ECMWF) Re-Analysis (ERA-40; Simmons and Gibson 2000) is used where appropriate to validate the presented simulations.

Section 2 describes the general circulation model used in this study and presents its seasonal zonal-mean zonal wind climatology at low and high vertical resolution in comparison to ERA-40. Section 3 discusses the climatology of the QBO as found in ERA-40 and compares the simulated QBO time series and composites of the westerly and easterly phases in zonal wind and temperature. Section 4 presents the composites of the forcing and compares the roles of resolved and parameterized wave-mean-flow interaction and of advection. Section 5 shows the improvements in the tropical upwelling, the atmospheric tape recorder signal in water vapor anomalies and the SAO. Section 6 discusses the sensitivity of the simulated QBO to modifications of the model resolution and the gravity wave forcing. Section 7 provides conclusions.

\section{Model description and climatology}

The numerical simulations of this study are carried out with the MAECHAM5 general circulation model, which is the middle-atmosphere configuration of the ECHAM5 model, for which details are given in Roeck- 

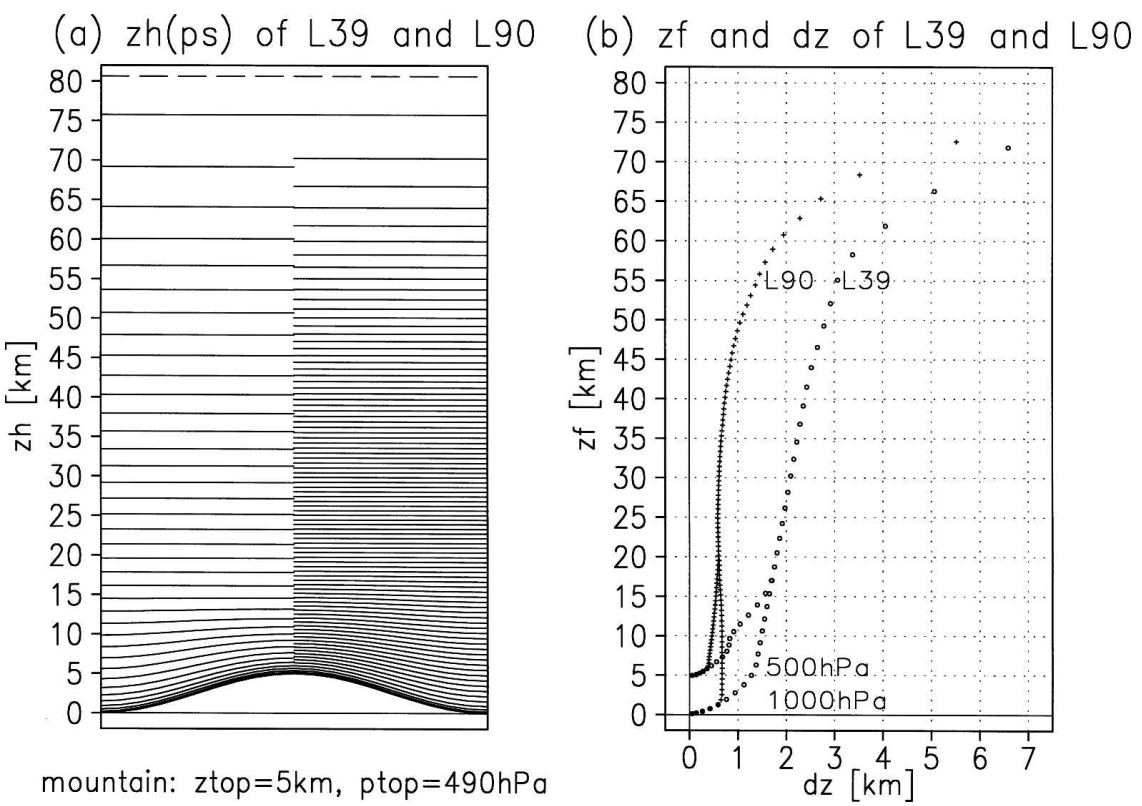

FIG. 1. Vertical grids of the MAECHAM5 GCM. (a) Standard height $(\mathrm{km})$ of the hybrid half levels (solid) and the uppermost full level (dashed) of the 39- and 90-layer grids over a sinusoidal mountain of 5-km altitude, assuming a constant scale height of $7 \mathrm{~km}$. (b) Full level standard height $(\mathrm{km})$ and layer thickness $(\mathrm{km})$ of the 39- (circles) and 90- $(+)$ layer grids for surface pressures of 1000 and $500 \mathrm{hPa}$.

ner et al. (2003). The vertical domain of MAECHAM5 extends from the surface up to $0.01 \mathrm{hPa}$, or approximately $80 \mathrm{~km}$. In addition to the processes represented in ECHAM5, MAECHAM5 includes also a parameterization for the momentum flux deposition from a continuous spectrum of unresolved gravity waves of tropospheric origin. This parameterization follows Hines (1997) and computes the vertical propagation and dissipation of continuous gravity wave spectra in 8 azimuths depending on the background atmospheric state and wave-wave interaction. Its implementation in MAECHAM5 is described in Manzini et al. (2006). None of the parameters in this scheme has been tuned for either obtaining or optimizing the QBO.

The MAECHAM5 model is available in two standard vertical resolutions, respectively, with 39 layers (as used in Manzini et al. 2006) and 90 layers. The latter configuration has been shown to allow the QBO simulation (Giorgetta et al. 2002) and is derived from the 39-layer model. Most simulations discussed in this work make use of the 90-layer grid (Fig. 1). The typical resolution of this grid is $700 \mathrm{~m}$ from the midtroposphere up to $3 \mathrm{hPa}$ and better than $1 \mathrm{~km}$ up to $1 \mathrm{hPa}$. The 39 - and the 90-layer grids, as well as other grids used in this study, share the lowermost 5 layers with the 19-layer grid of the tropospheric model version, in order to avoid direct effects on the parameterization of turbulent fluxes at the surface. Furthermore, these grids have the same uppermost layer so that the same dissipation formulation can be used in the uppermost layer. The Hines gravity wave drag (GWD) parameterization is used with the same parameters in the 39- and the 90layer versions.

The high- and low-resolution standard vertical grids with 90 and 39 layers, respectively, have been used in combination with T42 horizontal resolution in two experiments, respectively, labeled CL90 and CL39 (Table 1). The high-resolution experiment CL90 has a length of $30 \mathrm{yr}$ in order to include at least $10 \mathrm{QBO}$ cycles. The low-resolution experiment CL39 has a length of $10 \mathrm{yr}$. In both experiments the MAECHAM5 model is integrated with the lower boundary conditions specified by the monthly climatology of sea surface temperature (SST) and sea ice concentration of the period 1978 to 1996 [Atmospheric Model Intercomparison Project 2 (AMIP2) dataset]. Interannual variability in the general circulation of the experiments CL90 and CL39 therefore is unrelated to the prescribed boundary conditions. Effects of the observed interannual variability in SST on the circulation of the Northern Hemisphere middle atmosphere are discussed in Manzini et al. (2006). For the tropospheric climatology of ECHAM5, see Roeckner et al. (2006), which discusses also the sensitivity to horizontal and vertical resolution of the troposphere.

The ERA-40 data used here and in the following 
TABLE 1. List of experiments with climatological SST and ice. CL90 is the reference experiment with the specified characteristics. All other experiments are sensitivity experiments with the specified modifications. In this table, the length of experiments is shown in years (y), $n$ is the number of complete cycles measured at $20 \mathrm{hPa}, T$ is the average period of these cycles in months, and $T_{\min }$ and $T_{\max }$ are the shortest and longest cycles.

\begin{tabular}{|c|c|c|c|c|c|c|}
\hline Experiment & Comment & Length & $n$ & $T$ & $T_{\min }$ & $T_{\max }$ \\
\hline CL90 & $\mathrm{L} 90(d z=0.7 \mathrm{~km}) \mathrm{T} 42 v_{\mathrm{rms}}=1 \mathrm{~m} \mathrm{~s}^{-1}$ & $30 y$ & 12 & 29 & 25.3 & 33.2 \\
\hline CL39 & L39 & $10 y$ & na & na & na & na \\
\hline CL52 & $\operatorname{L} 52(d z=1.4 \mathrm{~km})$ & $10 y$ & na & na & na & na \\
\hline CL67 & $\mathrm{L} 67(d z=1.0 \mathrm{~km})$ & $10 y$ & 5 & 21.3 & 20.2 & 24.0 \\
\hline CT31 & $\mathrm{T} 31$ & $30 y$ & 13 & 26.2 & 23.4 & 30.2 \\
\hline CT63 & T63 & $30 y$ & 13 & 26.1 & 24.3 & 28.3 \\
\hline CM10 & $v_{\mathrm{rms}}=0.9 \mathrm{~m} \mathrm{~s}^{-1}$ & $10 y$ & 2 & 49.5 & 47.53 & 51.4 \\
\hline CP10 & $v_{\mathrm{rms}}=1.1 \mathrm{~m} \mathrm{~s}^{-1}$ & $10 y$ & 5 & 20.9 & 20.0 & 22.2 \\
\hline
\end{tabular}

sections are 6-hourly forecasts at the full resolution TL159/L60. These data stop at $0.1 \mathrm{hPa}$, but contamination from the model top boundary must be expected above $1 \mathrm{hPa}$. Only the years 1979 to 1999 will be considered in this work.
Figure 2 presents the climatology of the zonal-mean zonal wind, averaged over December, January, and February (DJF) and June, July, and August (JJA), respectively, for ERA-40, and the CL90 and CL39 experiments. Generally, both models are able to represent (a) E40: $U$ and $s(U)$ in DJF, $\mathrm{m} / \mathrm{s}$

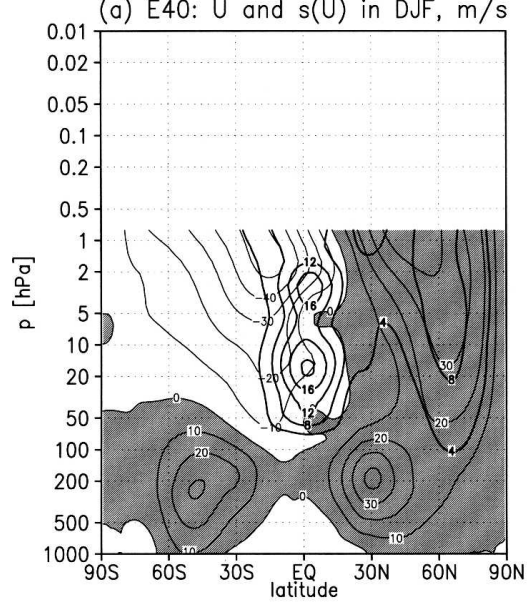

(f) E40: $U$ and $s(U)$ in JJA, $\mathrm{m} / \mathrm{s}$

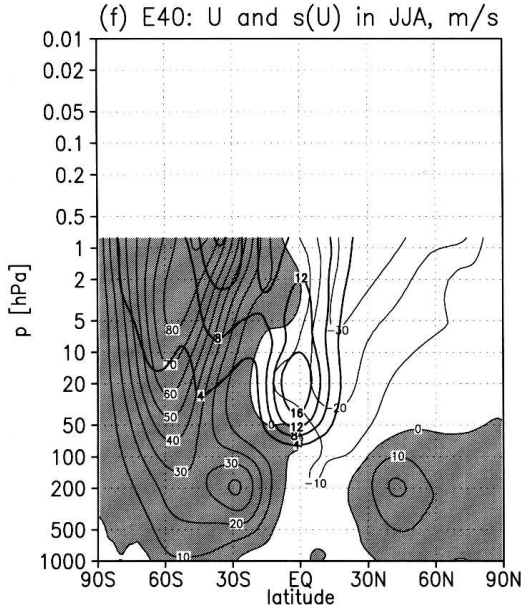

(b) CL90: $U$ and $s(U)$ in DJF, $\mathrm{m} / \mathrm{s}$

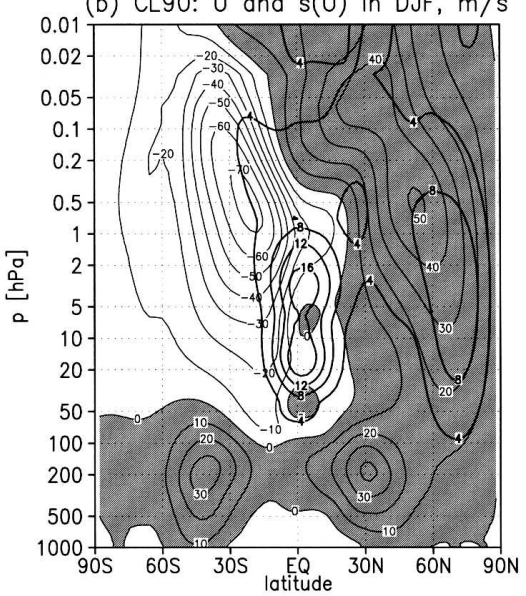

(e) CL90: $U$ and $s(U)$ in JJA, $\mathrm{m} / \mathrm{s}$

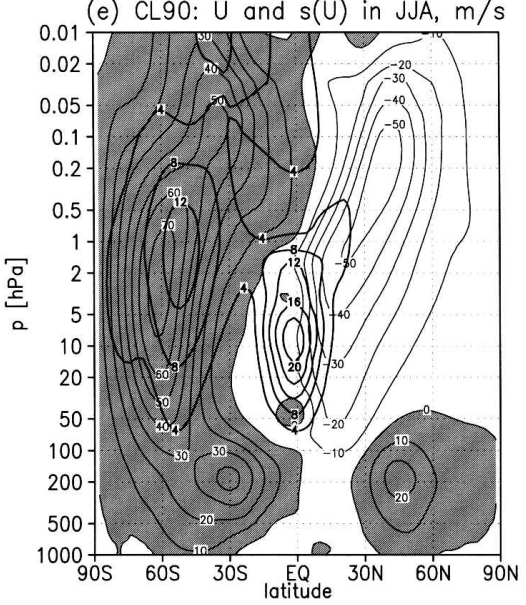

(c) CL39: $U$ and $s(U)$ in DJF, $\mathrm{m} / \mathrm{s}$

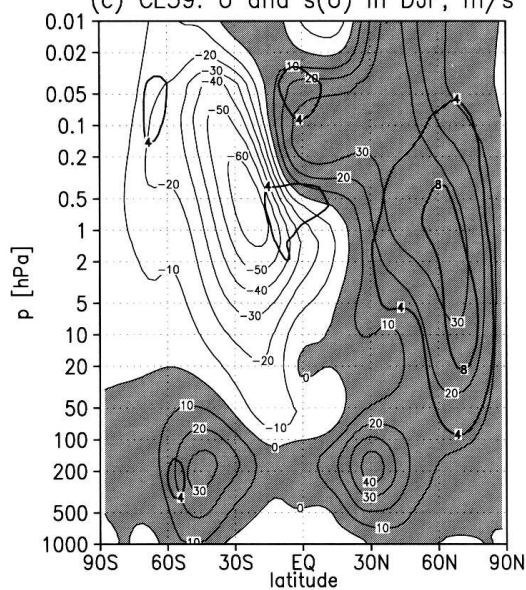

(f) CL39: $U$ and $s(U)$ in JJA, $\mathrm{m} / \mathrm{s}$

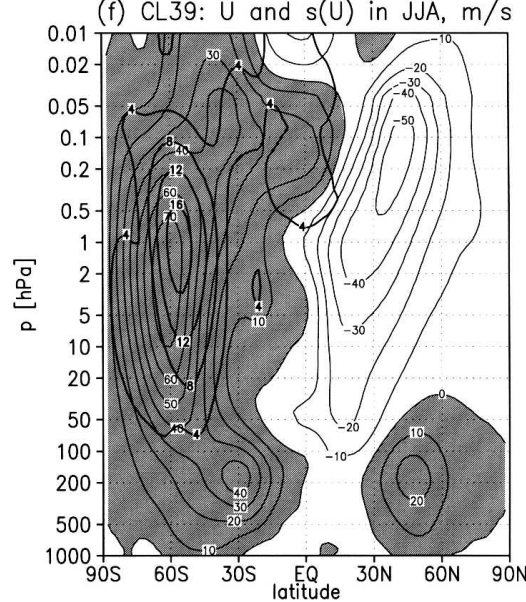

FIG. 2. Climatology of the zonal-mean zonal wind. Thin contours show the seasonal average $U$ in intervals of $10 \mathrm{~m} \mathrm{~s}^{-1}$, shading indicates seasonal mean westerlies, and bold contours show the standard deviation $(U)$ in intervals of $4 \mathrm{~m} \mathrm{~s}^{-1}$. Climatologies are shown for (a)-(c) DJF and (d)-(f) JJA for (left) ERA-40, (middle) experiment CL90, and (right) experiment CL39. 
realistic means of the subtropical tropospheric jets and their hemispheric and seasonal differences. The separation of the upper-tropospheric and lower-stratospheric jets in the Southern Hemisphere in JJA is improved in CL90 compared to CL39. The polar night jet in DJF is almost identical in strength in ERA-40 and CL90, though approximately $10 \mathrm{~m} \mathrm{~s}^{-1}$ weaker in CL39. This difference between the experiments is statistically not significant. The interannual standard deviation of the seasonal mean in the polar night jet is typically $8 \mathrm{~m} \mathrm{~s}^{-1}$ in ERA-40 and in both models. In JJA, the polar night jet maximizes in both models at 70 $\mathrm{m} \mathrm{s}^{-1}$ at $60^{\circ} \mathrm{S}$ near $2 \mathrm{hPa}$. ERA-40 shows a higher maximum of $90 \mathrm{~m} \mathrm{~s}^{-1}$ at the top of the underlying GCM. The standard deviation in the polar night jet domain is again comparable in ERA-40 and both experiments. The easterly circulations in the summer hemispheres are typically overestimated in both models compared to ERA-40.

In the equatorial stratosphere of the ERA-40 dataset, the major structure to be noticed is the high standard deviation; a manifestation of the QBO-related zonal wind variability. This feature is also found in the CL90 experiment but is completely missing in the CL39 experiment that has no QBO. The CL90 maximum in the DJF standard deviation is typically $16 \mathrm{~m} \mathrm{~s}^{-1}$ with a primary maximum between 10 and $30 \mathrm{hPa}$, and a secondary maximum above $5 \mathrm{hPa}$ in agreement with ERA40. In JJA, a single maximum occurs centered at 20 $\mathrm{hPa}$. The latitudinal width of the QBO-related maximum is typically $12^{\circ} \mathrm{S}$ to $12^{\circ} \mathrm{N}$, both in ERA-40 and CL90.

Although the climatological average of the zonalmean zonal wind may be of minor importance in the equatorial stratosphere, it should be noted that both the CL90 and ERA-40 seasonal averages show weak westerlies close to the equator near 5 and $50 \mathrm{hPa}$ in DJF and near $50 \mathrm{hPa}$ in JJA. The maxima are displaced toward the winter hemisphere. In CL39, there is one area of climatological westerlies at the equator near 20 $\mathrm{hPa}$ resulting from an excessively deep and strong semiannual oscillation in DJF. The differences between the equatorial wind profiles in CL90 and CL39 are small. However, they are important because they imply anomalies in the residual circulation; see section 5 .

In summary, concerning the seasonal zonal-mean zonal wind we have shown that the MAECHAM5 model has a realistic climatology in mid- and high latitudes of the middle atmosphere, which at the same horizontal resolution depends only little on the vertical resolution, similar to the findings of Hamilton et al. (1999). In the Tropics, the standard deviation of the seasonal zonal mean agrees very well with ERA-40 data for the CL90 experiment only. In addition, the equatorial climatological profile of the zonal-mean zonal wind is well reproduced in the CL90 experiment compared to ERA-40. The missing QBO in CL39 causes not only a severe bias in the variability, but also a small bias in the time mean zonal wind at the equator.

\section{Climatology of the QBO}

\section{a. The $Q B O$ in the zonal-mean zonal wind}

The QBO is commonly described by the zonal wind at equatorial stations, for example, at Singapore, which is sufficient because of the large degree of zonal symmetry of the phenomenon (Naujokat 1986). Merged data of equatorial stations therefore provide a zonal wind time series from 1953 onward (Labitzke et al. 2002), which is generally used as a reference description of the QBO evolution in the lower stratosphere, up to $10 \mathrm{hPa}$. However, comparisons away from the equator or at other levels make it necessary to refer to other data. The ERA-40 dataset that resolves the stratosphere completely can be used for this purpose (Randel et al. 2004; Uppala et al. 2004). It has been shown that the equatorial zonal wind of ERA-40, at the station sites or in the zonal mean, can be used for most purposes as an alternative to radiosonde data to characterize the QBO (Baldwin and Gray 2005), since zonal wind observations of equatorial radiosondes are assimilates in ERA-40, amongst many other observations. As shown in Bengtsson et al. (2004), the accurate representation of the equatorial zonal wind below $10 \mathrm{hPa}$ depends mostly on these radiosonde wind observations, and far less on the assimilation of satellite radiance observations. The QBO in ERA-40 (Fig. 3a) is remarkably improved compared to older reanalyses (Pawson and Fiorino 1998). However, in the upper stratosphere, between 10 and $3 \mathrm{hPa}$, there are differences in the zonal wind structures in ERA-40 before and after 1987, also visible in Fig. 22 of Uppala et al. (2004), where the full time series from 1957 to 2002 is shown. Before 1987, the QBO is hardly present above $7 \mathrm{hPa}$, while the QBO cycles after 1987 start at 3-5 hPa.

The CL90 simulation includes about 12 QBO cycles over $30 \mathrm{yr}$. The average period is 29 months, whereas the shortest and longest cycles last for 25 and 33 months, respectively. Observational values are 28, 22, and 34 months for average, minimum, and maximum cycle length (Baldwin et al. 2001). Figure 3 shows the analyzed QBO of the years 1979 to1999 and the simulated QBO of the years 6 to 26 averaged between $5^{\circ} \mathrm{N}$ and $5^{\circ} \mathrm{S}$. Here the time frame of the simulation is chosen such that the initial profile has easterlies between 

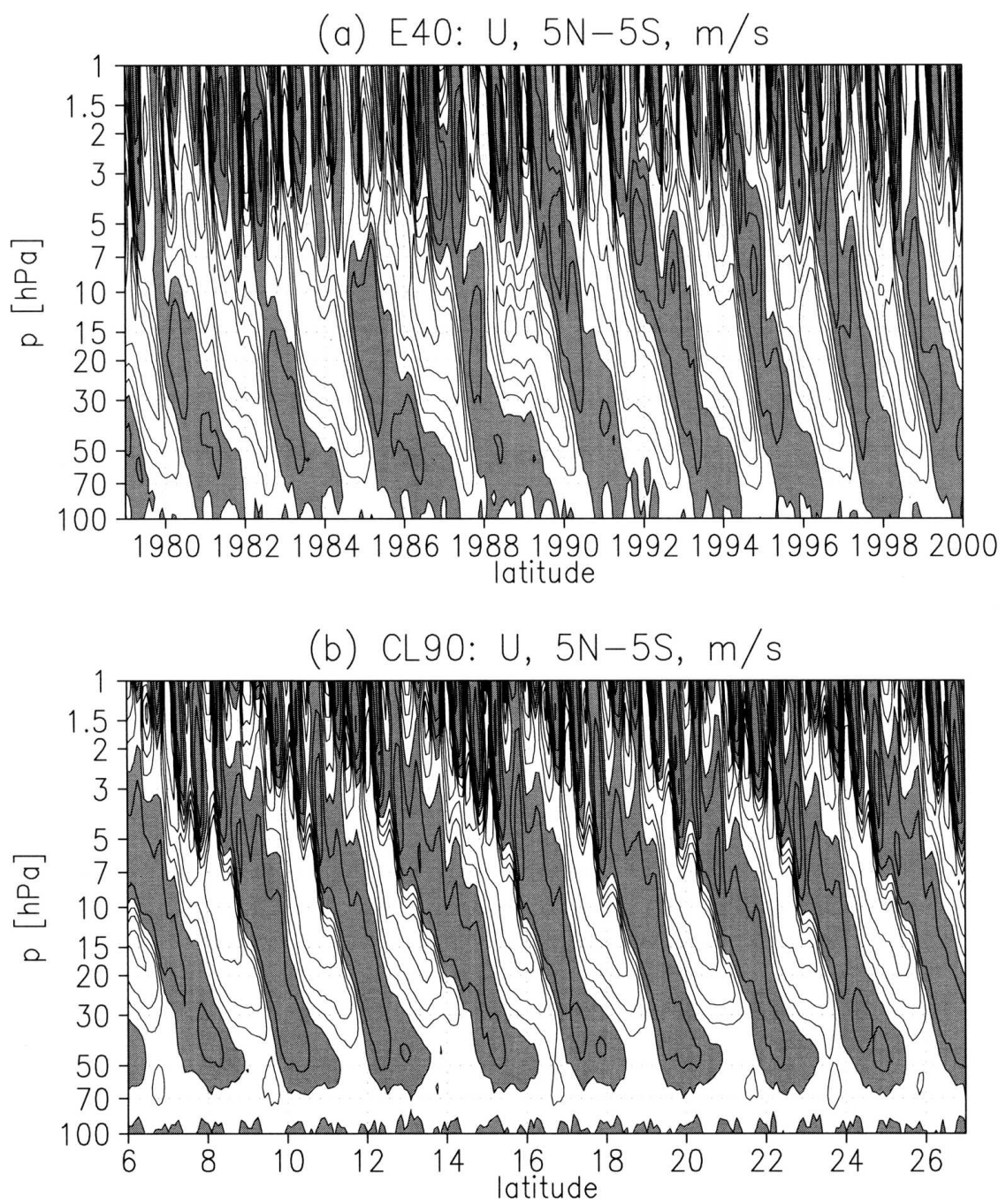

FIG. 3. QBO in zonal-mean zonal wind $U\left(\mathrm{~m} \mathrm{~s}^{-1}\right)$ between $5^{\circ} \mathrm{N}$ and $5^{\circ} \mathrm{S}$. (a) Years 1979 to 1999 in ERA-40, and (b) years 6 to 26 in experiment CL90. Shading indicates westerlies. The contour interval is $10 \mathrm{~m} \mathrm{~s}^{-1}$.

30 and $70 \mathrm{hPa}$, as in January 1979, to facilitate the time series comparison. The model has a strong QBO cycle exposing the observed main characteristics: the westerly phases have amplitudes of typically 10 to $15 \mathrm{~m} \mathrm{~s}^{-1}$ and propagate without loss in amplitude from levels near 10 to about $50 \mathrm{hPa}$. The easterly phases have amplitudes of typically -30 to $-35 \mathrm{~m} \mathrm{~s}^{-1}$ above $20 \mathrm{hPa}$ and decay toward lower levels. Westerly shear zones are more pronounced than the easterly shear zones. Below $30 \mathrm{hPa}$, the westerly phase dominates, and there is variability in the termination of the westerly phase. Compared to ERA-40, the maximum of the modeled westerly phases is slightly stronger. Below $20 \mathrm{hPa}$, however, the easterly phase decrease is stronger than observed, and below $50 \mathrm{hPa}$, the simulated $\mathrm{QBO}$ attenuates quickly and there is no significant signal at $90 \mathrm{hPa}$, unlike in ERA-40. In addition, the simulated QBO is more regular than that in ERA-40, which has to be expected because (a) the prescribed gravity wave sources are constant in time and (b) the prescribed SST has no interannual variability. The vertical upward extent of the simulated QBO corresponds to that in ERA40 after 1988, with westerly phases starting typically at $5 \mathrm{hPa}$.

The approximate peak-to-peak amplitude of the QBOs in Fig. 3 can be estimated following Baldwin and Gray (2005). The resulting QBO amplitude profiles are displayed in Fig. 4 (cf. Fig. 4 of Baldwin and Gray 2005). The maximum amplitudes are very similar: 55 $\mathrm{m} \mathrm{s}^{-1}$ and $57 \mathrm{~m} \mathrm{~s}^{-1}$ in ERA-40 and CL90. However, compared to ERA-40 the simulated QBO is weaker between $15 \mathrm{hPa}$ and the tropopause, but stronger be- 


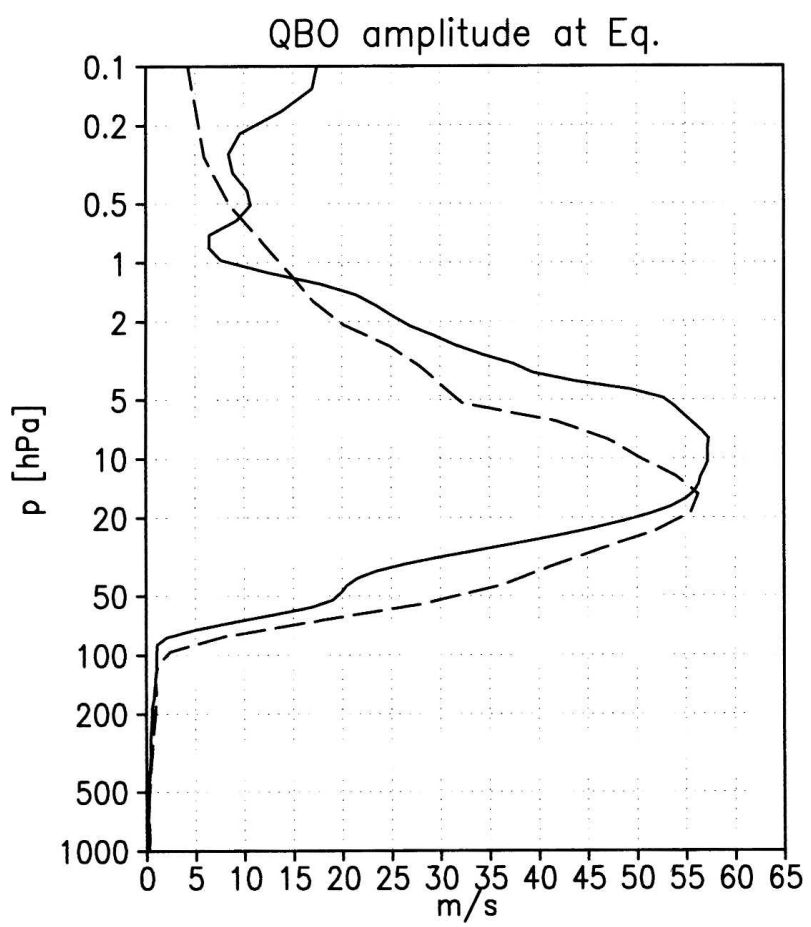

FIG. 4. Peak-to-peak amplitudes of the QBO time series of Fig. 3 in $\mathrm{m} \mathrm{s}^{-1}$ for CL90 (solid) and ERA-40 (dashed).

tween $15 \mathrm{hPa}$ and the stratopause. The latter difference is related to the weak QBO signal in ERA-40 above 10 hPa before 1987.

The average properties of the QBO cycles in ERA40 and CL90 are assessed by means of composites of westerly and easterly phases with respect to their time of onset at the equator at $20 \mathrm{hPa}$. The composites shown in Fig. 5 include 9 QBO cycles from 1979 to 2001 in ERA-40 and 12 cycles in CL90. The actual fields used here are defined by $U_{r}=U-U_{\mathrm{cm}}+U_{\mathrm{ca}}$, where $U_{\mathrm{cm}}$ and $U_{\mathrm{ca}}$ are the climatological annual cycle and the climatological annual mean of $U$. This allows in good approximation a separation of annual and quasibiennial variability. The annual mean is included so that the characteristic asymmetries of the westerly and easterly phases are retained.

In the time-pressure cross section (Figs. 5a,b), the westerly phase in CL90 exceeds $15 \mathrm{~m} \mathrm{~s}^{-1}$ above $20 \mathrm{hPa}$, while the westerly phase of ERA-40 does not reach 15 $\mathrm{m} \mathrm{s}^{-1}$ at any level, because the cycles before 1987 are weaker in the upper stratosphere (Fig. 3a). The easterly phases have maxima of -35 and $-30 \mathrm{~m} \mathrm{~s}^{-1}$ in ERA-40 and in CL90, respectively. The major difference occurs in the downward propagation of the easterly phases below $20 \mathrm{hPa}$. Near $50 \mathrm{hPa}$, the easterly phase is significantly weaker in CL90 than in ERA-40, and below $70 \mathrm{hPa}$, there is a general easterly bias in CL90 causing weaker westerlies and stronger easterlies compared to ERA-40.

The latitude-time cross sections at $20 \mathrm{hPa}$ (Figs. 5c,d) show the westerly and easterly phases embedded in the tropical background easterly flow. The maxima of the westerly phases are $12 \mathrm{~m} \mathrm{~s}^{-1}$ in ERA-40 as well as in CL90. However, the latitudinal width of the westerly phase is slightly larger in ERA-40, about $10^{\circ} \mathrm{N}$ to $\mathrm{S}$, than in CL90, about $8^{\circ} \mathrm{N}$ to $\mathrm{S}$. In both datasets, the westerly phase is narrower in latitude than the easterly phase, and the westerly phase onset occurs first at the equator, while the easterly phase onset happens more evenly over the equatorial latitudes (Hamilton 1984).

The latitude-pressure cross sections at the time of onset of westerlies are shown in Figs. 6a,b. The simulated westerly phase has the same vertical depth as in ERA-40. However, the westerly phase maximum of CL90 is stronger by $5 \mathrm{~m} \mathrm{~s}^{-1}$, and the latitudinal gradients as well as the leading vertical shear are steeper than in ERA-40. The strongest difference occurs in the easterly phase below $20 \mathrm{hPa}$, where the jet is nearly suppressed between 40 and $70 \mathrm{hPa}$, as found already in the time series comparison (Fig. 3).

The latitude-pressure cross sections of the easterly phase composite are displayed in Figs. 6c,d. In this case, the westerly phase below the onset point is well captured in CL90 and has the same vertical depth as in ERA-40. The easterly phases have different depths because of the earlier onset of the following westerly phase already present in CL90 near $2 \mathrm{hPa}$.

The simulated QBO in zonal-mean zonal wind is realistic in many aspects compared to ERA-40. A significant deviation is identified in the suppression of the easterly jet between 70 and $40 \mathrm{hPa}$. Furthermore, the simulated westerly jets are slightly narrower than in ERA-40.

\section{b. The temperature signal of the $Q B O$}

The secondary meridional circulation of the QBO causes positive and negative temperature anomalies in regions of dynamically forced vertical descent and ascent, respectively (Randel et al. 1999). These temperature signals are strongest in the vertical shear layers of the QBO, where the secondary meridional circulation has the strongest vertical velocities. Secondary signals of opposite sign occur in the nonequatorial Tropics, where the return branches of the secondary meridional circulation are located.

The QBO signals in the residual circulation and hence in the temperature are reproduced in the experiment CL90. The composites of the temperature anomalies, defined as $T_{r}=T-T_{\mathrm{cm}}$, are shown in Fig. 7. In the 
(a) E40: W composite in Ur $(\mathrm{m} / \mathrm{s})$ at Eq.

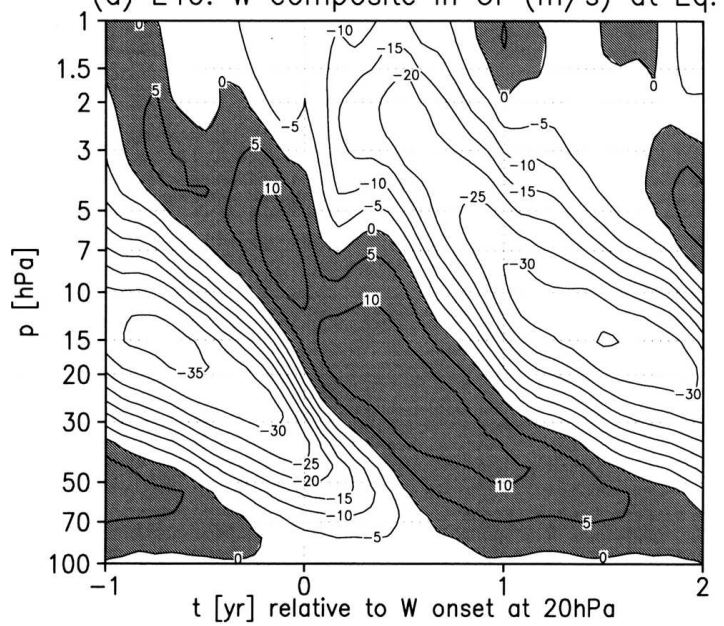

(c) E40: W composite in $\mathrm{Ur}(\mathrm{m} / \mathrm{s})$ at $20 \mathrm{hPa}$

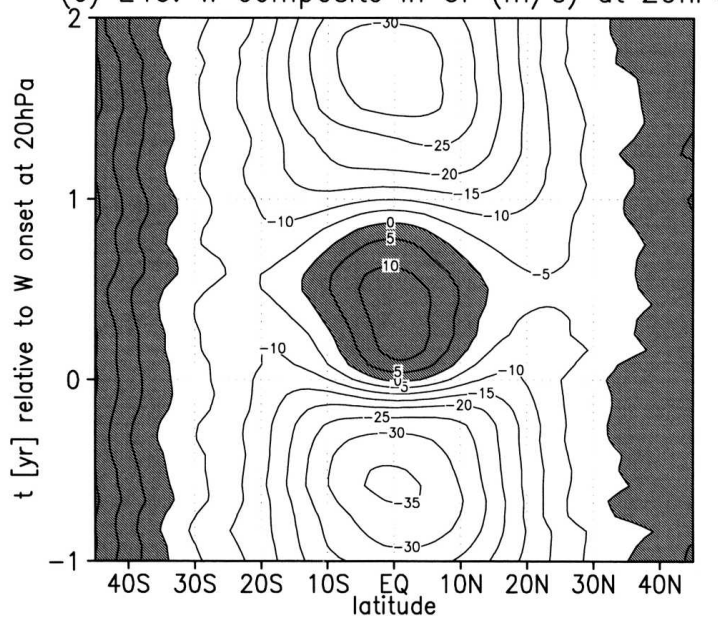

(b) CL90: W composite in Ur $(\mathrm{m} / \mathrm{s})$ at Eq.

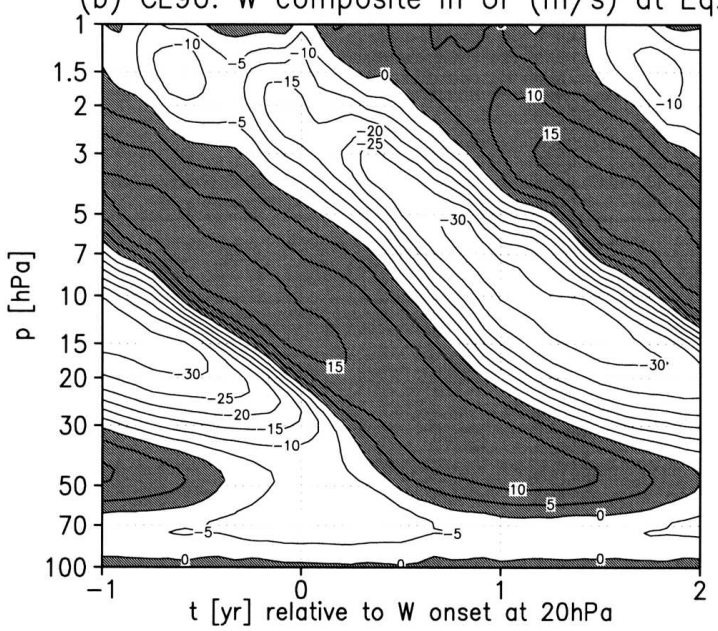

(d) CL90: W composite in Ur $(\mathrm{m} / \mathrm{s})$ at $20 \mathrm{hPa}$

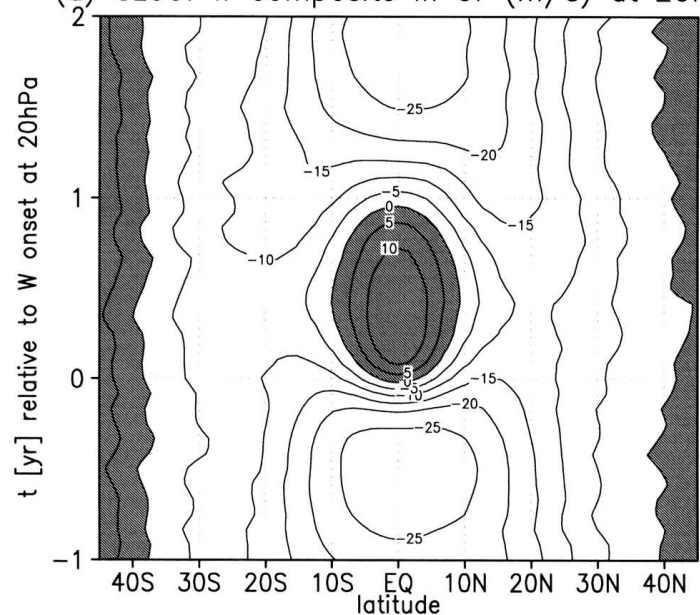

FIG. 5. Composite of the QBO in the residual zonal-mean zonal wind $U_{r}\left(\mathrm{~m} \mathrm{~s}^{-1}\right)$ with respect to the onset time of residual westerlies at $20 \mathrm{hPa}$. Time-pressure cross section at the equator in (a) ERA-40 and (b) CL90 and latitude-time cross section at $20 \mathrm{hPa}$ in (c) ERA-40 and (d) CL90. Shading indicates westerlies, the contour interval is $5 \mathrm{~m} \mathrm{~s}^{-1}$, and time is shown in units of years.

westerly phase composites (Figs. 7a,b) the temperature anomaly in the leading shear layer near $20 \mathrm{hPa}$ (cf. Figs. $6 a, b)$ is $3.5 \mathrm{~K}$ in ERA-40 and $2.5 \mathrm{~K}$ in CL90. The anomalies in the associated return branches, extending to about $40^{\circ}$ latitude, are typically 1 to $1.5 \mathrm{~K}$ in ERA-40 and in CL90. It should be noted that seasonal effects in the QBO temperature signal (Randel et al. 1999) are suppressed in the composites discussed here so that the pattern is strongly symmetric with respect to the equator. In the upper stratosphere, the model shows a much larger negative temperature signal of $-2.5 \mathrm{~K}$ compared to $-0.5 \mathrm{~K}$ in ERA-40, which is explained by the new westerly jet already established in CL90 at $5 \mathrm{hPa}$, but at this time not yet present in ERA-40. In the lower stratosphere the negative temperature anomaly of the model is $-0.5 \mathrm{~K}$ only compared to $-1.5 \mathrm{~K}$ in ERA-40, which is related to the suppressed easterly jet in the model (cf. Figs. 6a,b).

Also for the easterly phase composites (Figs. 7c,d) the anomaly patterns correspond very well between ERA-40 and CL90. Differences are found again in the amplitude of the equatorial anomalies, which are stronger in ERA-40 in the middle and lower stratosphere, but weaker in the upper stratosphere than in CL90, related to the differences identified in the zonal wind composites (Figs. 6c,d). The anomalies in the Southern Hemisphere return branches at $12 \mathrm{hPa}$ are equally strong in CL90 and ERA-40. In the Northern Hemisphere ERA-40 shows a stronger anomaly of $1.5 \mathrm{~K}$ at $27^{\circ} \mathrm{N}$ compared to $1 \mathrm{~K}$ at $22^{\circ} \mathrm{N}$ in CL90.

For both QBO phases, it is found that the temperature signal differs mostly at the equator in the leading 
(a) E40: W composite in Ur $(\mathrm{m} / \mathrm{s})$ at $\mathrm{t}=1$

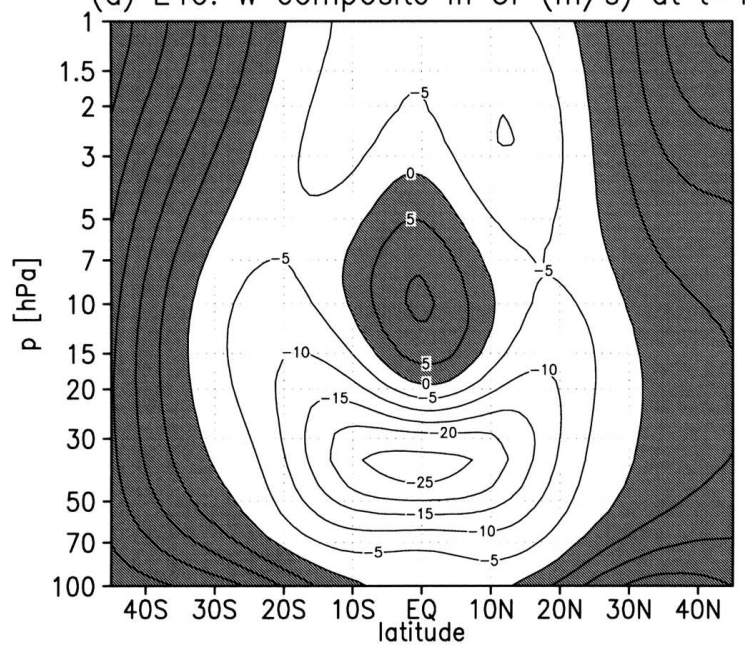

(c) E40: E composite in Ur $(\mathrm{m} / \mathrm{s})$ at $\mathrm{t}=1$

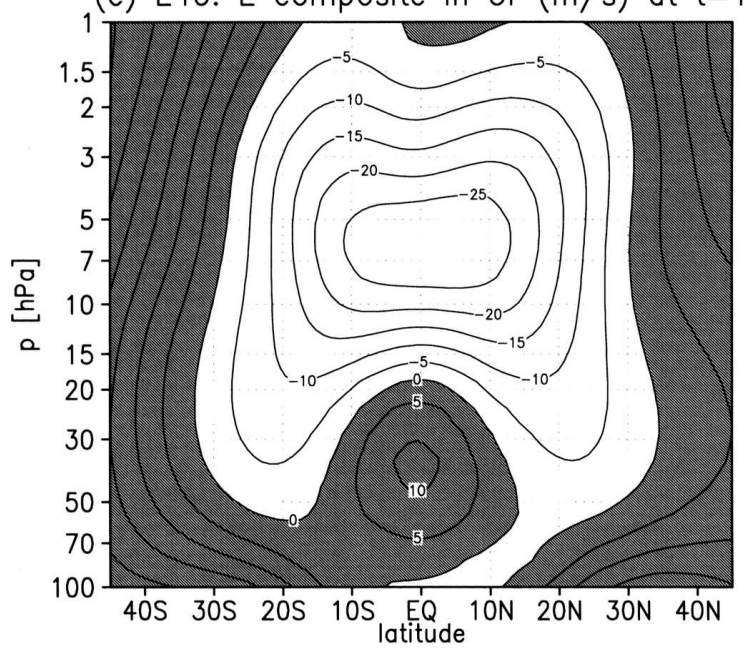

(b) CL90: W composite in Ur $(\mathrm{m} / \mathrm{s})$

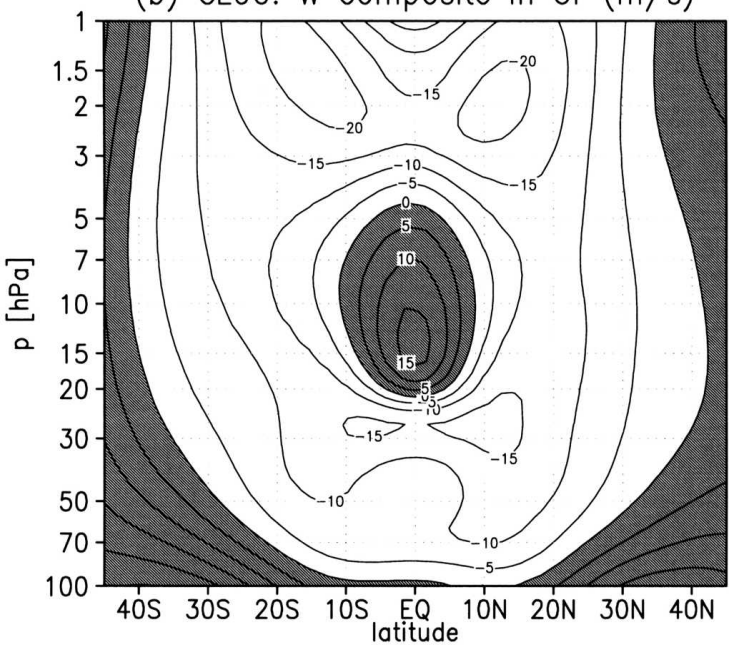

(d) CL90: E composite in Ur $(\mathrm{m} / \mathrm{s})$

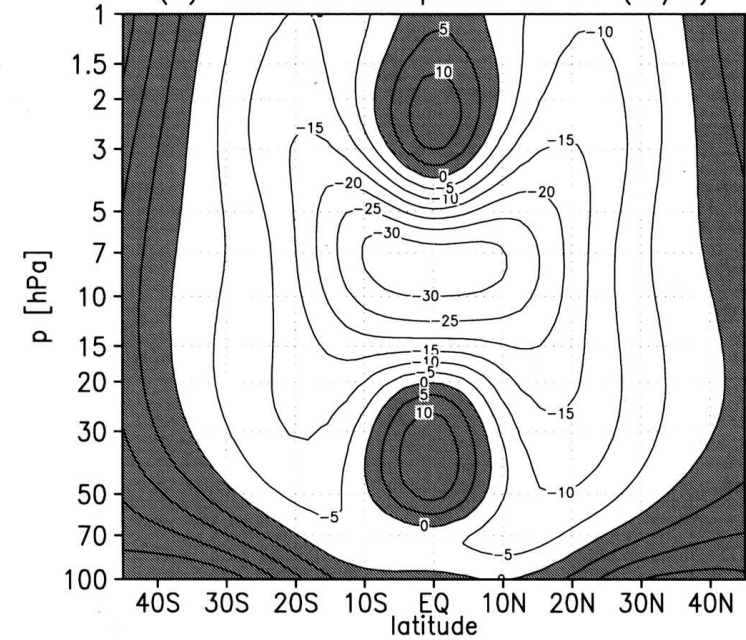

FIG. 6. Composite of the QBO in the residual zonal-mean zonal wind $U_{r}\left(\mathrm{~m} \mathrm{~s}^{-1}\right)$ with respect to the onset time of residual (top) westerlies and (bottom) easterlies at $20 \mathrm{hPa}$ in (left) ERA-40 and (right) CL90. Shading indicates westerlies, and the contour interval is $5 \mathrm{~m} \mathrm{~s}^{-1}$.

zonal wind shear. These differences can be analyzed in the approximate thermal wind balance relationship at the equator [Andrews et al. 1987, their Eq. (8.2.2)]:

$$
T^{\prime}=L^{2} H \beta R^{-1} \partial U / \partial \mathrm{z}
$$

where $L$ is meridional scale length, $H=7 \mathrm{~km}$ is nominal scale height, $\beta$ is the latitudinal derivative of the Coriolis parameter, $R$ is the gas constant for dry air, and $z$ is log-pressure height.

The vertical shears $\partial U / \partial z$ are estimated between 15 and $30 \mathrm{hPa}$ for the westerly phase $\left(\partial U / \partial z_{\mathrm{ERA}-40}=25\right.$ $\left.\mathrm{m} \mathrm{s}^{-1} / 4 \mathrm{~km}, \partial U / \partial z_{\mathrm{CL} 90}=30 \mathrm{~m} \mathrm{~s}^{-1} / 4 \mathrm{~km}\right)$ and between 10 and $30 \mathrm{hPa}$ for the easterly phase $\left(\partial U / \partial z_{\mathrm{ERA}-40}=\right.$ $\left.-30 \mathrm{~m} \mathrm{~s}^{-1} / 7 \mathrm{~km}, \partial U / \partial z_{\mathrm{CL} 90}=-40 \mathrm{~m} \mathrm{~s}^{-1} / 7 \mathrm{~km}\right)$. If then the meridional length scale is chosen as $L_{\text {ERA-40 }}=$
$1000 \mathrm{~km}$ and $L_{\mathrm{CL} 90}=800 \mathrm{~km}$, based on Figs. 5 or 6 , then the estimated temperature signals are $3.5(\mathrm{~W}$, ERA-40), 2.7 (W, CL90), -2.4 (E, ERA-40) and -2 K (E, CL90), similar to the maxima in Fig. 7. In this simple model, the smaller temperature signal in CL90 is mostly explained by the smaller meridional width of the simulated westerly jet due to the $L^{2}$ factor in Eq. (1).

\section{Forcing of the simulated QBO}

The QBO results from the net effect of various processes acting on the zonal momentum, the most important being the wave-mean-flow interaction and the advection. In MAECHAM5, the wave-mean-flow inter- 
(a) E40: $W$ composite in $\operatorname{Tr}(K)$ at $t=1$

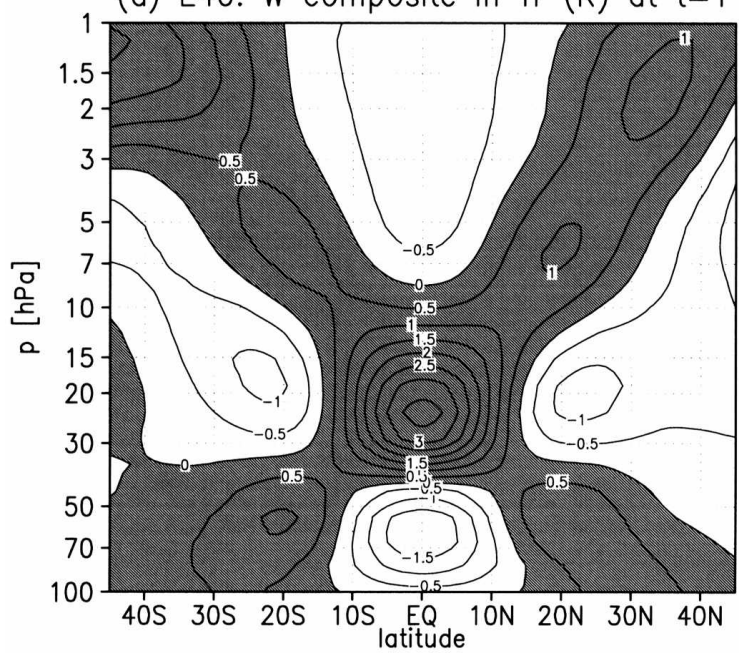

(c) E40: E composite in $\operatorname{Tr}(K)$ at $t=1$

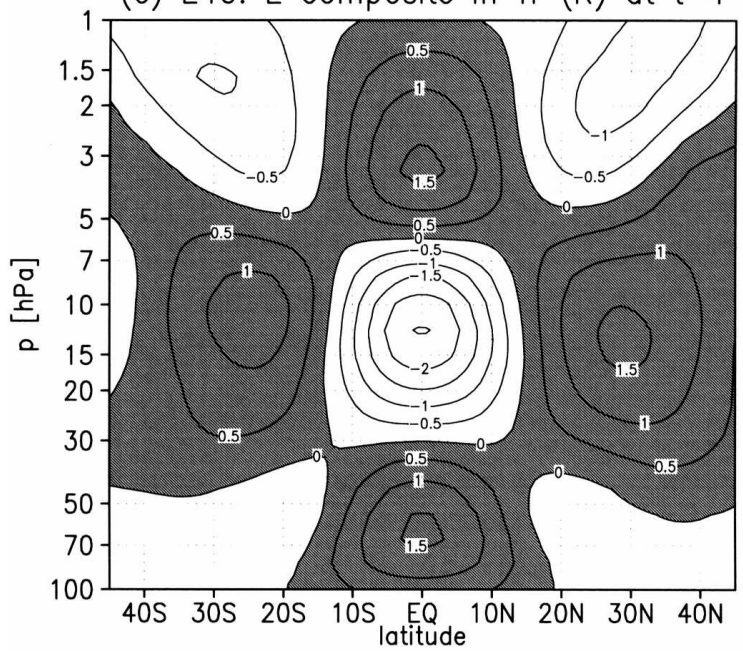

(b) CL90: $W$ composite in $\operatorname{Tr}()$ at $t=1$

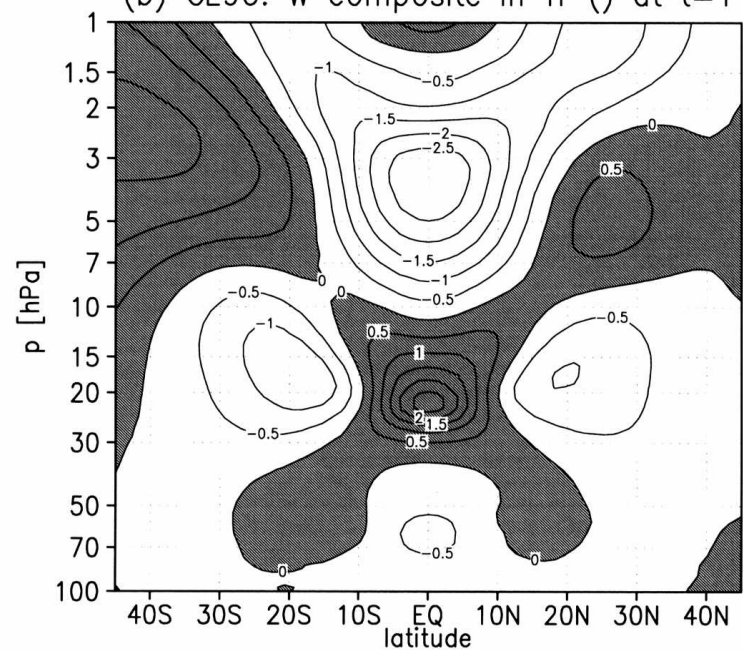

(d) CL90: $E$ composite in $\operatorname{Tr}()$ at $t=1$

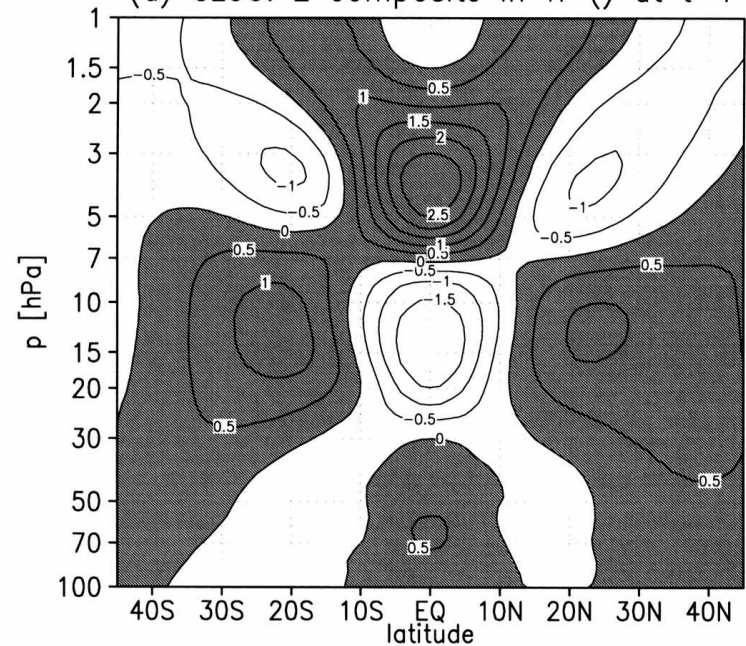

FIG. 7. Same as in Fig. 6, but for composite of the QBO signal in the residual temperature $T_{r}(\mathrm{~K})$. Shading indicates positive temperature anomalies, and the contour interval is $0.5 \mathrm{~K}$.

action involves both the resolved dynamical effects including waves up to the truncation limit at wavenumber 42 in the CL90 experiment, and the parameterized effects of the interaction of the gravity waves with the resolved wind. The resolved wave-mean-flow interaction is diagnosed as the divergence of the EliassenPalm (EP) flux $\mathbf{F}_{\mathrm{EP}}$, including the vertical and meridional components, while the parameterized GWD, which considers vertical wave propagation only, is directly accessible within the GCM integration. In the following we discuss the tendencies of the zonal-mean zonal wind $U$ in the transformed Eulerian mean framework [e.g., Andrews et al. 1987, their Eqs. (3.5.1a) to (3.5.3b)] considering the main terms $\partial U /\left.\partial t\right|_{\nabla \cdot \mathbf{F}_{\mathrm{EP}}}, \partial U /$ $\left.\partial t\right|_{\mathrm{GWD}}$, and $\partial U /\left.\partial t\right|_{\mathrm{adv}}$ of the equation for the zonalmean zonal wind $U$ :

$$
\begin{aligned}
\partial U / \partial t= & \partial U /\left.\partial t\right|_{\nabla \cdot \mathbf{F}_{\mathrm{EP}}}+\partial U /\left.\partial t\right|_{\mathrm{GWD}}+\partial U /\left.\partial t\right|_{\mathrm{adv}} \\
& +\partial U /\left.\partial t\right|_{\mathrm{res}} \\
\partial U /\left.\partial t\right|_{\boldsymbol{\nabla} \cdot \mathbf{F}_{\mathrm{EP}}}= & {\left[a(\cos \varphi) \rho_{0}\right]^{-1} \boldsymbol{\nabla} \cdot \mathbf{F}_{\mathrm{EP} \cdot} } \\
\partial U /\left.\partial t\right|_{\mathrm{GWD}}= & f_{\text {Hines }}(u, v, N) \\
\partial U /\left.\partial t\right|_{\mathrm{adv}}= & -\left(v^{*}, w^{*}\right)\left\{(a \cos \varphi)^{-1} \partial[(\cos \varphi)(U)] / \partial \varphi\right. \\
& -f, \partial U / \partial z\} . \\
\partial U /\left.\partial t\right|_{\mathrm{res}}= & \text { residual forcing, }
\end{aligned}
$$

where $a$ is the earth's radius, $\varphi$ is latitude, $z$ is log-pressure height, $f$ is the Coriolis parameter, $\rho_{0}$ is density, $(u, v)$ is zonal and meridional wind, and $N$ is BruntVäisälä frequency. 
(a) CL90: W composite in $\mathrm{dU} / \mathrm{dt} \mid \operatorname{divEP}(\mathrm{m} / \mathrm{s} / \mathrm{d})$
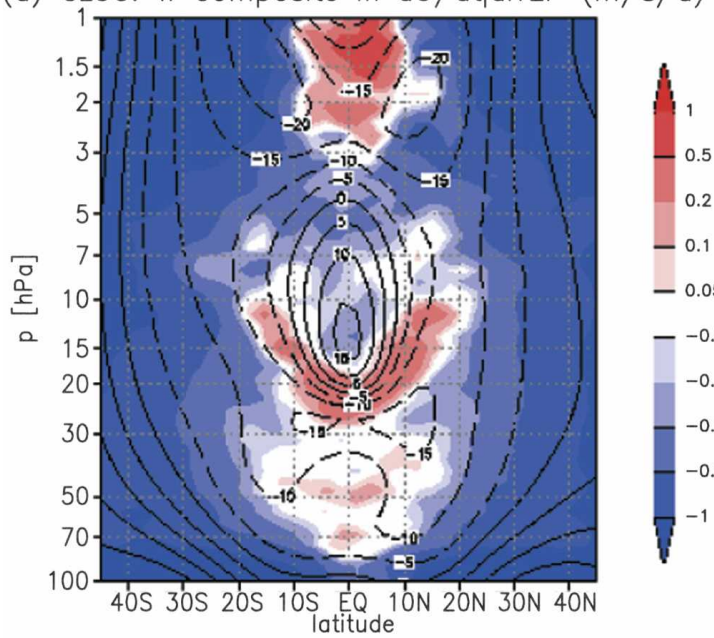

(c) CL90: W composite in $\mathrm{dU} / \mathrm{dt} \mid \mathrm{gw}(\mathrm{m} / \mathrm{s} / \mathrm{d})$

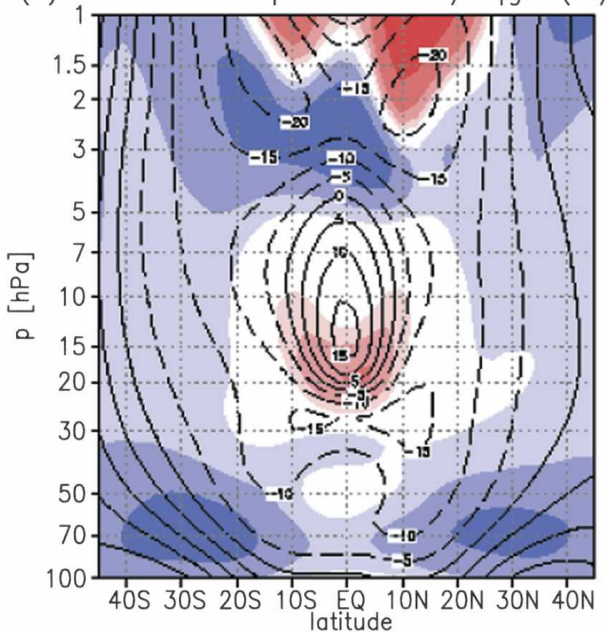

(b) CL90: E composite in dU/dt|divEP (m/s/d)

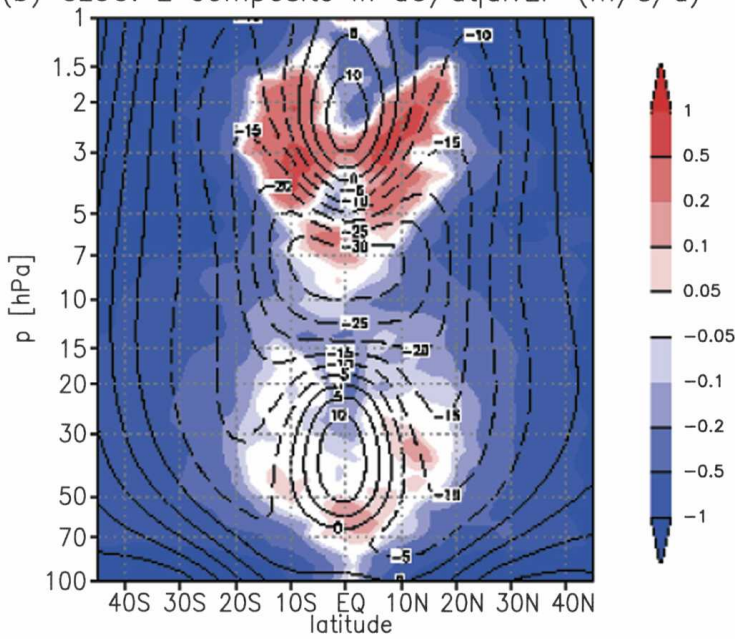

(d) CL90: E composite in $\mathrm{dU} / \mathrm{dt} \mid \mathrm{gw}(\mathrm{m} / \mathrm{s} / \mathrm{d})$

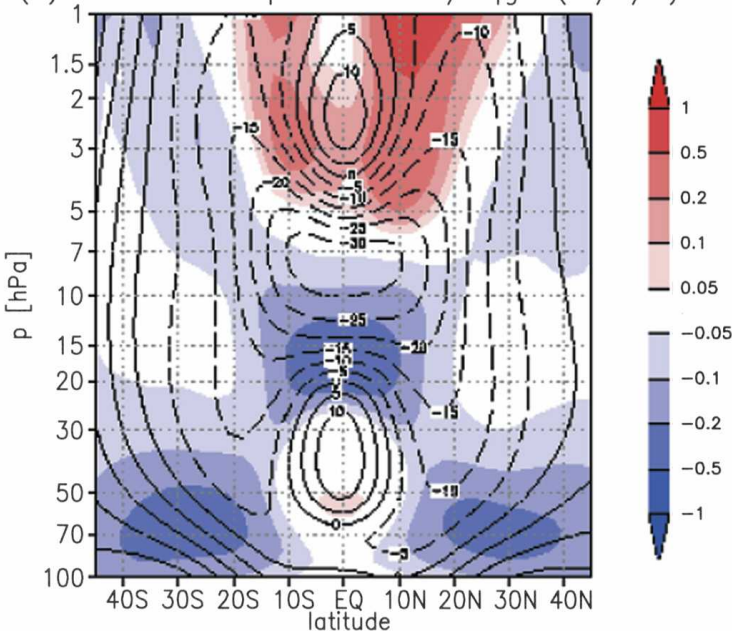

FIG. 8. Composites of tendencies (top) $\partial U /\left.\partial t\right|_{\nabla \cdot \mathbf{F}_{\mathrm{EP}}}$ and (bottom) $\partial U /\left.\partial t\right|_{\mathrm{GWD}}$ for (left) westerly phase and (right) easterly phase. Color shading shows tendencies $\partial U / \partial t$ in a logarithmic scale $\left(\mathrm{m} \mathrm{s}^{-1}\right.$ day $\left.{ }^{-1}\right)$; contours show the composites of the QBO phase in intervals of $5 \mathrm{~m} \mathrm{~s}^{-1}$.

Contributions of $\partial U /\left.\partial t\right|_{\mathbf{V} \cdot \mathbf{F}_{\mathrm{EP}}}$ and $\partial U /\left.\partial t\right|_{\mathrm{GWD}}$ to westerly and easterly phases are shown in Fig. 8 as composites of zonal wind tendencies $\partial U / \partial t_{r}=\partial U / \partial t-\partial U / \partial t_{\mathrm{cm}}+$ $\partial U / \partial t_{\mathrm{ca}}$ including the annual means. In the westerly phase composite (Fig. 8a), the resolved dynamics $\partial U /$ $\left.\partial t\right|_{\boldsymbol{\nabla} \cdot \mathbf{F}_{\mathrm{EP}} r}$ causes a well-defined arc of westerly tendencies in the westerly shear zone leading the jet at about $12 \mathrm{hPa}$. The westerly tendencies have maxima of 0.2 to $0.5 \mathrm{~m} \mathrm{~s}^{-1}$ day $^{-1}$ and extend from the equator to approximately $20^{\circ}$ latitude. This arclike structure is embedded in a background easterly forcing of -0.2 to -0.5 $\mathrm{m} \mathrm{s}^{-1}$ day $^{-1}$. In the lower stratosphere, westerly forcing occurs between 40 and $80 \mathrm{hPa}$ close to the equator, explaining the bite out in the easterly jet at this level as discussed before.

In the easterly phase composite (Fig. 8b), there is no particular forcing structure in the easterly shear layer between 10 and $30 \mathrm{hPa}$, except for the background easterly forcing. An arc of westerly acceleration is found again in the leading westerly shear layer of the westerly jet centered at $40 \mathrm{hPa}$. A similar structure is found below the new westerly phase at $2-3 \mathrm{hPa}$. Here the composite shows strongest tendencies of 0.5 to $1 \mathrm{~m} \mathrm{~s}^{-1}$ day $^{-1}$ off the equator between $5^{\circ}$ and $15^{\circ}$ latitude. At the equator near $4 \mathrm{hPa}$ instead, the tendency in the leading westerly shear zone is negative and a positive tendency occurs just below in the trailing shear layer of the easterly jet. This positive tendency initiates the erosion of the easterly jet at the equator, a typical feature of the QBO evolution (Hamilton 1984).

Near the equator, the parameterized tendencies $\partial U /\left.\partial t\right|_{\mathrm{GWD}, r}$ (Figs. 8c,d) are significant above $30 \mathrm{hPa}$ 

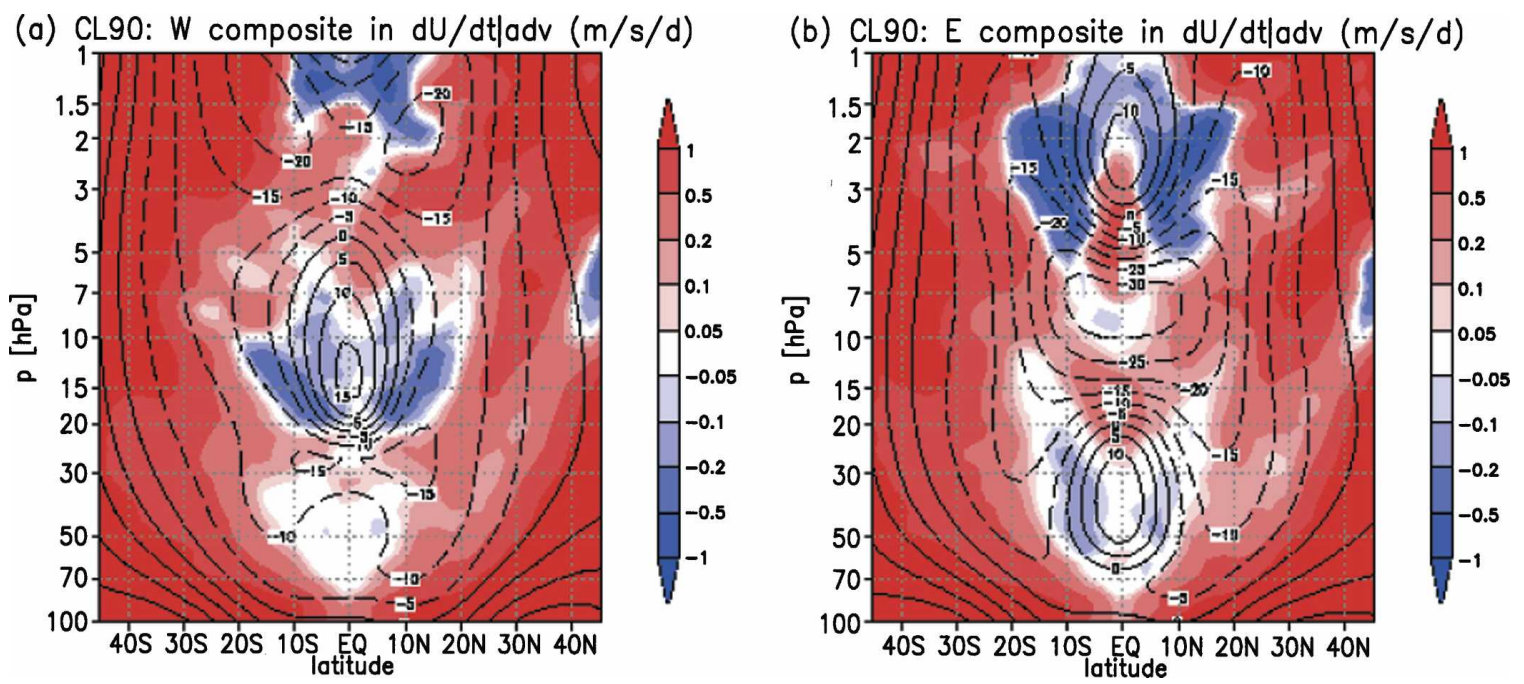

FIG. 9. Advective tendencies $\partial U /\left.\partial t\right|_{\text {adv }}$ for (a) the composite westerly phase and (b) the composite easterly phase. Color shading shows tendencies $\partial U / \partial t$ in a logarithmic scale $\left(\mathrm{m} \mathrm{s}^{-1}\right.$ day $\left.^{-1}\right)$; contours show the composites of the QBO phase in intervals of $5 \mathrm{~m} \mathrm{~s}^{-1}$.

only, where tendency up to, respectively, 0.2 and -0.4 $\mathrm{m} \mathrm{s}^{-1}$ day $^{-1}$ are found in the leading shear layer of the westerly and easterly jet. The gravity wave drag shows clear equatorial maxima confined within $10^{\circ}$ latitude leading the jet starting at $20 \mathrm{hPa}$. The filtering effect of shear layers on the gravity wave momentum flux is visible in Fig. 8d, where two equally strong westerly jets are present in the lower and upper stratosphere at 40 and $2 \mathrm{hPa}$. The gravity wave drag in the shear zone of the lower jet shows a maximum at the equator, whereas the westerly drag in the shear zone of the upper jet has two maxima off the equator with weaker westerly drag near the equator above the lower westerly jet.

Figure 9 displays the composites of the advective tendencies $\partial U /\left.\partial t\right|_{\mathrm{adv}, r}$ for the westerly and easterly phases. The equatorial convergence of the secondary meridional circulation in the westerly jets causes easterly tendencies, thus confining the westerly jets close to the equator, as seen between 10 and $20 \mathrm{hPa}$ in Fig. 9a and between 30 and $50 \mathrm{hPa}$ and 1.5 and $4 \mathrm{hPa}$ in Fig. $9 \mathrm{~b}$. Similarly, the secondary meridional circulation divergence in the easterly jets causes westerly tendencies and is important for the latitudinal confinement of the easterly jet. The downward and upward branches of the secondary meridional circulation below and above westerly jets cause positive tendencies, as seen clearly below and above the easterly jet in Fig. 9b. This contributes to strongly convex leading and trailing shear zones of the westerly jets and to flat or concave shear zones of the easterly jets. The advective tendencies in the midstratosphere are typically -0.5 to $0.5 \mathrm{~m} \mathrm{~s}^{-1}$ day $^{-1}$ between $15^{\circ}$ and $20^{\circ} \mathrm{N}$ and $\mathrm{S}$, which is in the same range as the contribution by the wave-mean-flow terms.

A comparison of the different sources of tendencies is displayed in Fig. 10 for the equatorial band of $5^{\circ} \mathrm{N}$ to $5^{\circ} \mathrm{S}$, where zonal wind tendencies are directly relevant to the vertical propagation of the QBO. In the case of the westerly composite, the total tendency by EP flux divergence, gravity wave drag, and advection (black solid line) show a distinct peak of $0.5 \mathrm{~m} \mathrm{~s}^{-1}$ day $^{-1}$ in the shear layer below the westerly maximum at $15 \mathrm{hPa}$. The strongest contribution is given by the divergence of the EP flux (about $60 \%$ of the peak) followed by the gravity wave drag, which has a maximum of $40 \%$ of the total peak value. This maximum is positioned slightly higher than that of the EP flux divergence and has a larger depth than the peak of the EP flux divergence. The advective tendencies do not exceed $0.1 \mathrm{~m} \mathrm{~s}^{-1}$ day $^{-1}$ in the leading shear layer of the westerly jet because of the weak easterly jet in the lower stratosphere. Still the profile of the advective tendency compensates the vertical offset of the gravity wave drag profile, such that the total peak has the same position and depth as the peak of the EP flux divergence. A similar picture is found for the leading shear layer of the westerly jet in the lower stratosphere in the easterly composite, except for the reduced amplitudes.

In the middle and upper stratosphere, advection plays a more dominant role, as seen in the leading shear layer of the easterly phase composite. Here the advection counteracts the onset of the easterly phase across the whole shear layer, with a maximum of $0.4 \mathrm{~m} \mathrm{~s}^{-1}$ day $^{-1}$. The advective tendency almost completely compensates the gravity wave drag. The EP flux divergence 

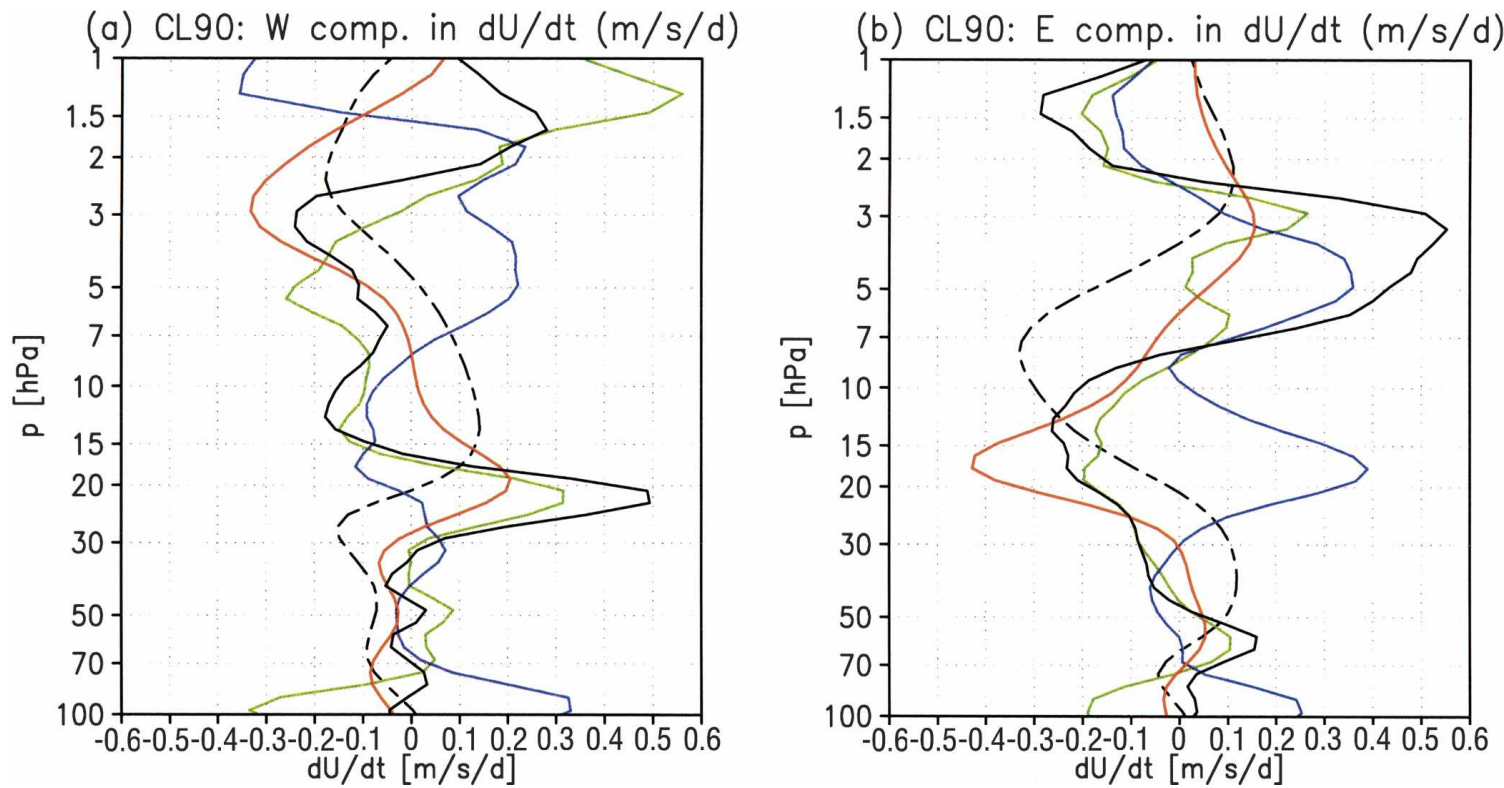

FIG. 10. Vertical profiles of the QBO in units of $100 \mathrm{~m} \mathrm{~s}^{-1}$ (black dashed) and tendencies $\left(\mathrm{m} \mathrm{s}^{-1}\right.$ day $\left.^{-1}\right) \partial U /\left.\partial t\right|_{\nabla \cdot \mathbf{F}_{\mathrm{EP}}}$ (green), $\partial U /\left.\partial t\right|_{\mathrm{GWD}}$ (red), $\partial U /\left.\partial t\right|_{\text {adv }}$ (blue), and their sum (black) averaged from $5^{\circ} \mathrm{N}$ to $5^{\circ} \mathrm{S}$ for (a) the composite westerly phase and (b) the composite easterly phase.

peaks at $-0.2 \mathrm{~m} \mathrm{~s}^{-1}$ day $^{-1}$ or about $50 \%$ of the gravity wave drag. Because of the effective compensation of advection and gravity wave drag, the net tendency has about the same amplitude as that of the EP flux divergence. A similar picture is found for the easterly phase in the upper stratosphere in the westerly phase composite. Advection is an important process for the downward propagation of the westerly phase in the upper stratosphere, as seen in the easterly phase composite. Here advection strongly contributes to the deceleration in the trailing shear layer of the easterly jet.

The results found here confirm the forcing of the QBO by a broad spectrum (Giorgetta et al. 2002). In this composite-specific analysis, the forcing of the westerly and easterly phases shows some phase-specific features. The downward shift of the westerly phase is dominated by the resolved and parameterized wavemean-flow interaction. The resolved waves contribute about $60 \%$ of the forcing, and gravity waves contribute about $40 \%$. Advection plays a minor role for the onset of the westerly phase but contributes as a negative forcing in the core of the jet. The easterly phase forcing and decay are strongly influenced by advection. The downward propagation occurs as a net result of resolved and parameterized wave-mean-flow interaction contributing to the formation and propagation, and a strong opposing effect of the advection. Here the effect of gravity waves is twice that of the resolved waves.

\section{QBO effects in the tropical stratosphere}

Until now it has been shown that the improved wave-mean-flow interaction results in the simulation of the QBO in zonal wind and its temperature signal with realistic details. Furthermore, the improvements in the representation of the wave-mean-flow interaction in the model are also found to have an impact on the simulation of (a) the annual mean tropical upwelling and the atmospheric tape recorder in moisture anomalies, and (b) the SAO in zonal wind at the stratopause.

\section{a. Tropical upwelling and the atmospheric tape recorder}

The differences between the equatorial wind profiles in CL90 and CL39, as assessed in section 2 are small. However, they are important because of the implied anomalies in the residual circulation. A climatological westerly wind maximum at the equator implies a meridional convergence in $v^{*}$ and hence a climatologically weaker (stronger) upwelling below (above) the core of the jet. Figure 11a shows the climatological annual mean upwelling averaged between $10^{\circ} \mathrm{N}$ and $10^{\circ} \mathrm{S}$ for the CL90 and CL39 experiments. The profiles have identical upwelling rates near $100 \mathrm{hPa}$, and both profiles show a minimum of approximately $0.1 \mathrm{~mm} \mathrm{~s}^{-1}$ in the lower stratosphere, but the elevation of this minimum differs. In CL90 the minimum is just below 50 $\mathrm{hPa}$, in good agreement with the minimum position of $60 \mathrm{hPa}$ found in Rosenlof et al. (1997). In CL39, the 
(a) Annual mean ws in CL90, CL39, $\mathrm{mm} / \mathrm{s}$

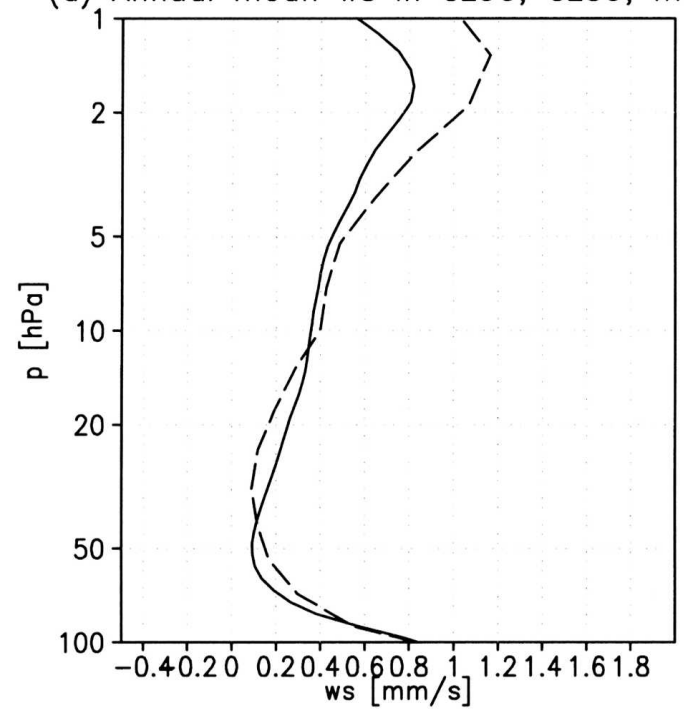

(b) CL90: atm. tape recorder, ppmv

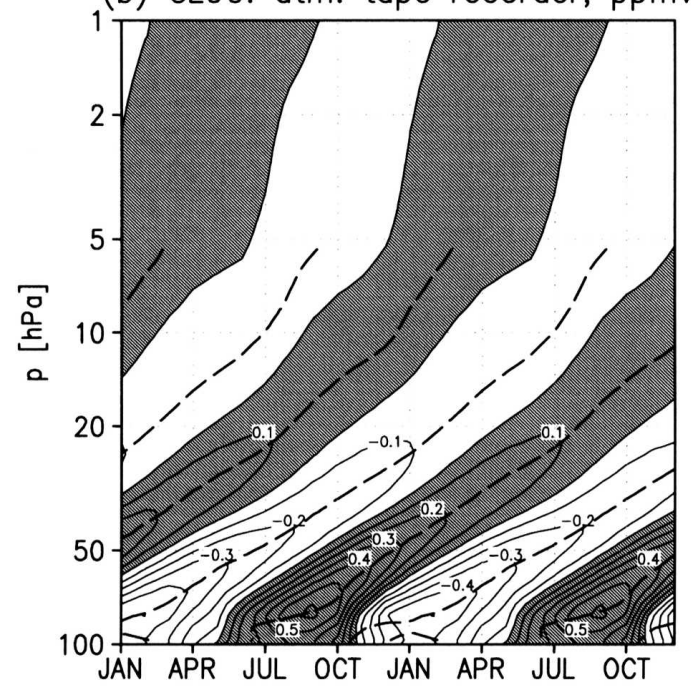

(c) CL39: atm. tape recorder, ppmv

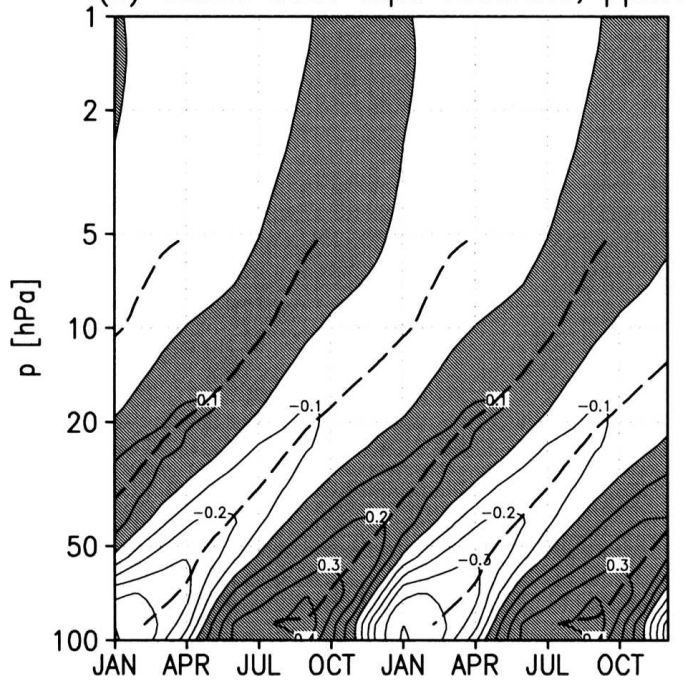

upwelling minimum is at $30 \mathrm{hPa}$ so that the climatological upwelling in the lower stratosphere is probably overestimated below $40 \mathrm{hPa}$.

The position of the upwelling minimum is important for the tracer transport, as shown here for the climatology of the upward motion of moisture anomalies in the equatorial stratosphere, known as the atmospheric tape recorder (Mote et al. 1996). The tape recorder signal consists of negative moisture anomalies created at the tropical tropopause in boreal winter and positive ones starting in late summer. The anomalies propagate upward until the signal is dissipated above $20 \mathrm{hPa}$. Mote et al. (1996) present typical transit times of 13.5 and 17 months from the tropopause to 20 and $10 \mathrm{hPa}$, respectively. Both experiments reproduce the general pattern of upward-moving moisture anomalies (Figs. 11b,c). In CL90, the climatological transit times are 14 and 18 months from $100 \mathrm{hPa}$ up to 20 and $10 \mathrm{hPa}$, respectively, nearly identical to those of Mote et al. (1996). In CL39, where the upwelling below $40 \mathrm{hPa}$ is faster, the signal propagation takes 8 months and 12 months from 100 $\mathrm{hPa}$ to 20 and $10 \mathrm{hPa}$, respectively, thus strongly overestimating the upward motion of the moisture anomalies.

The improvement in the annual mean upwelling, as described here, may become more relevant in chemistry climate models, where biases in the tropical upwelling, as presented here for CL39, must have negative impacts on the vertical transport of source gases like methane or nitrous oxide (Steil et al. 2003).

\section{b. The semiannual oscillation}

The SAO in zonal wind depends on wave-mean-flow interaction, similar to the QBO, and meridional advection during solstice seasons imposing the regular period. These waves are propagated from their level of origin in the troposphere across the stratosphere, where vertical propagation conditions depend on the quasibiennially varying background wind profiles. The QBO exerts filtering on the vertically propagating wave spectra, such that a QBO dependence of the SAO must be expected, and is indeed found (Burrage et al. 1996). At the same time it is observed that the QBO westerly

$\leftarrow$

FIG. 11. (a) Annual mean tropical upwelling $w^{*}\left(\mathrm{~mm} \mathrm{~s}^{-1}\right)$ in the experiments CL90 (solid) and CL39 (dashed). Atmospheric tape recorder signal: upward propagation of zonal-mean moisture anomalies between $10^{\circ} \mathrm{N}$ and $10^{\circ} \mathrm{S}$ in (b) CL90 and (c) CL39. Shading indicates positive anomalies; contour intervals are 0.1 ppmv. Dashed lines indicate the evolution of the maxima and minima in the vertical profiles of moisture anomalies. 
(a) CL90: clim. U at Eq., $\mathrm{m} / \mathrm{s}$

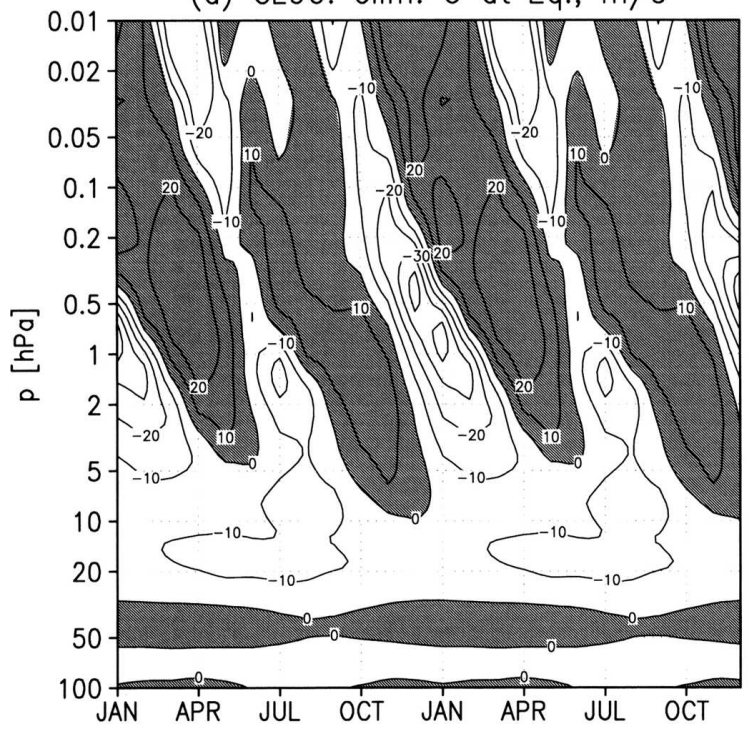

(c) CL90: $\operatorname{Var}(U)$ at Eq. , $\mathrm{m} 2 / \mathrm{s} 2$

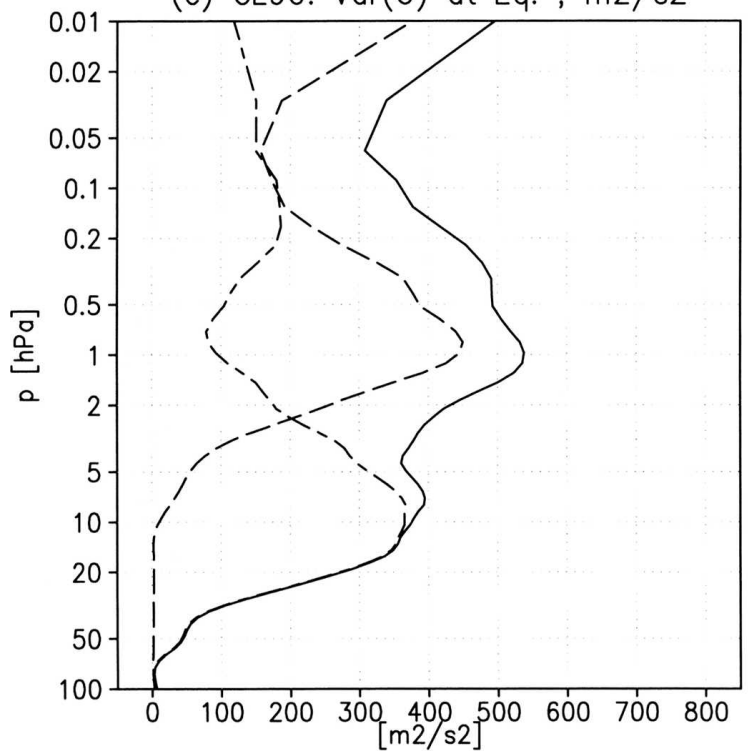

(b) CL39: clim. U at Eq., $\mathrm{m} / \mathrm{s}$

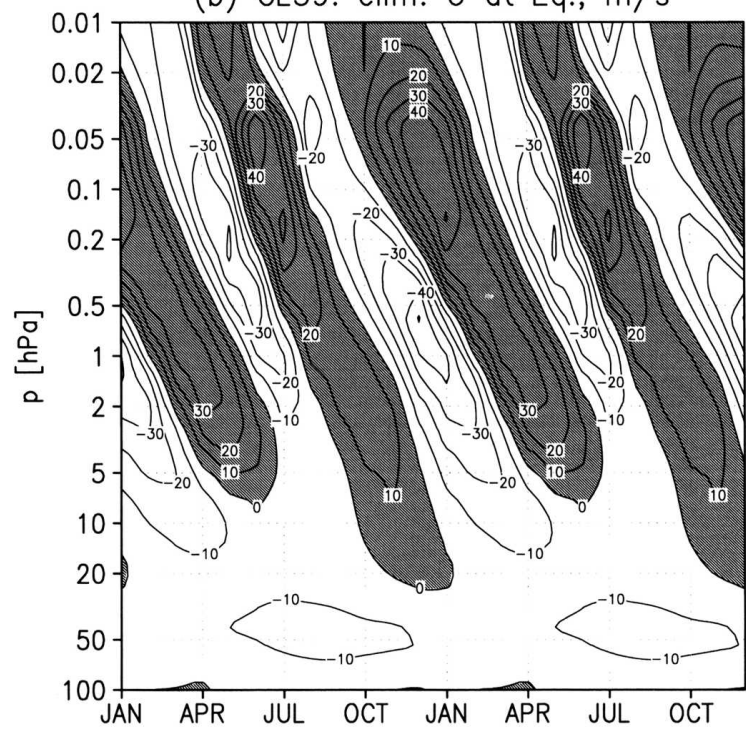

(d) CL39: $\operatorname{Var}(U)$ at Eq. , $\mathrm{m} 2 / \mathrm{s} 2$

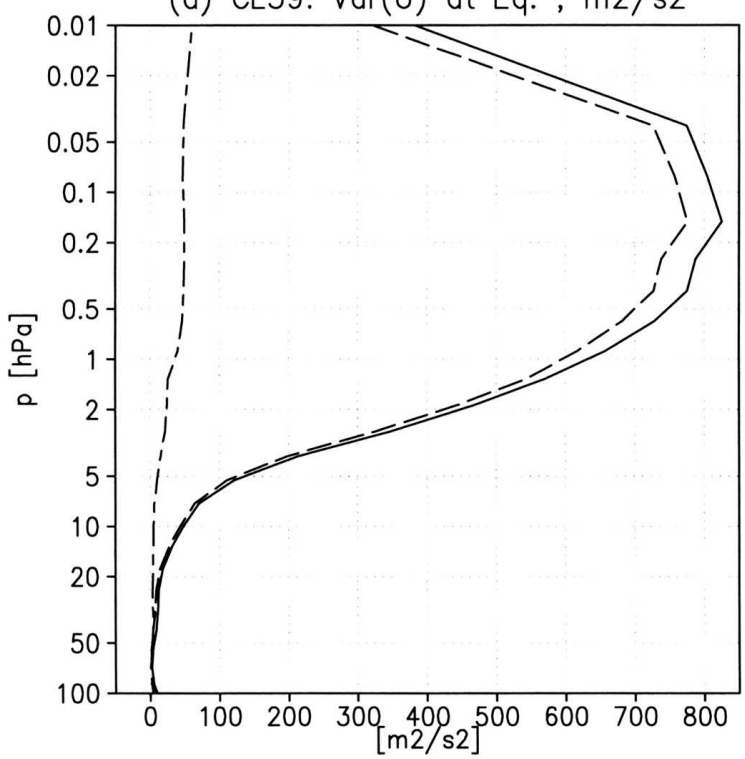

FIG. 12. SAO as seen in the climatological annual cycle of the monthly zonal-mean zonal wind $U\left(\mathrm{~m} \mathrm{~s}^{-1}\right)$ averaged between $5^{\circ} \mathrm{S}$ and $5^{\circ} \mathrm{N}$ in (a) CL90 and (b) CL39. Shading indicates westerlies; the contour interval is $10 \mathrm{~m} \mathrm{~s}^{-1}$. Monthly variance $\operatorname{Var}(U)$ (solid), variance of the climatological annual cycle $\operatorname{Var}\left(U_{\mathrm{cm}}\right)$ (dashed), and the difference $\operatorname{Var}(U)-\operatorname{Var}\left(U_{\mathrm{cm}}\right)$ (dotted-dashed) in (c) CL90 and (d) CL39; units are $\mathrm{m}^{2} \mathrm{~s}^{-2}$.

phases often start in SAO westerly phases (Dunkerton and Delisi 1997), so that the SAO and QBO are dynamically coupled to some degree. Also in CL90, the stratospheric $\mathrm{SAO}$ varies with the $\mathrm{QBO}$, as seen in the deeper propagation of westerlies when the QBO westerly phase descends to the lower stratosphere, and the QBO westerly phases start from an SAO westerly phase (Fig. 3b). However, in the following the focus is not on the coupling effects but rather on the differences in the simulated SAO that occur between the experi- ments CL90, which includes the QBO, and CL39, where the QBO is missing. These differences are discussed for the stratopause SAO. The mesopause SAO is neglected because it cannot be resolved properly in the MAECHAM5 model, where the top layer is at 0.01 $\mathrm{hPa}$.

The climatological SAOs of both experiments are shown in Fig. 12. In CL90, the SAO shows the typical seasonal asymmetry with a stronger first cycle starting in Northern Hemisphere winter (Delisi and Dunkerton 
1988). During the first cycle, easterlies and westerlies reach typically -40 and $+20 \mathrm{~m} \mathrm{~s}^{-1}$; during the second cycle zonal winds are weaker, reaching -20 and +15 $\mathrm{m} \mathrm{s}^{-1}$. The maxima occur near $1 \mathrm{hPa}$. These values compare reasonably well with early rocket wind observations (Belmont et al. 1975) or estimates from High Resolution Doppler Imager (HRDI) retrievals (Burrage et al. 1996). In CL39, the differences between the first and second cycle are less evident and the amplitudes are generally stronger. Easterlies and westerlies reach typically -40 and $+45 \mathrm{~m} \mathrm{~s}^{-1}$, though at higher levels near $0.1 \mathrm{hPa}$ where the observed SAO is weak. Clearly, the SAO in CL39 has too strong maximum values, although the amplitude at $1 \mathrm{hPa}$ is comparable to CL90. Another difference is found in the vertical extent of the SAO, which is excessively deep in CL39 with westerlies propagating from the top of the model down to $20 \mathrm{hPa}$.

Significant differences are found also in the variance associated with the SAOs in both experiments. This becomes obvious in a comparison of the variances in the equatorial zonal-mean zonal wind (Figs. 12c,d). Variances of the entire monthly mean time series are shown in solid. In CL90, the profile grows from the troposphere to a first maximum of $400 \mathrm{~m}^{2} \mathrm{~s}^{-2}$ above 10 $\mathrm{hPa}$ and shows an absolute maximum of $540 \mathrm{~m}^{2} \mathrm{~s}^{-2}$ at the stratopause before decaying to $300 \mathrm{~m}^{2} \mathrm{~s}^{-2}$ at 0.05 hPa. In CL39, the monthly variance grows initially more slowly assuming a value of $400 \mathrm{~m}^{2} \mathrm{~s}^{-2}$ at $2 \mathrm{hPa}$ only, but grows further to a broad maximum of $800 \mathrm{~m}^{2}$ $\mathrm{s}^{-2}$ below $0.1 \mathrm{hPa}$. Hence, the total variance differs significantly between the experiments. The difference in the stratosphere is a manifestation of the QBO present in one experiment only, while the difference above the QBO domain is a result of the QBO at lower levels filtering the waves that are producing the SAO. The dashed profiles show the variance of the zonal-mean zonal wind climatology, which by construction highlights the SAO strength and vertical extent. In CL90, there is a clear maximum of $450 \mathrm{~m}^{2} \mathrm{~s}^{-2}$ at the stratopause, decaying nearly linearly above and below the stratopause. Half-maximum values are found near 2 and $0.2 \mathrm{hPa}$, thus confining the stratosphere/mesosphere SAO to about this vertical range, which agrees with observations. In CL39, the variance of the climatology is nearly identical to the full variance, indicating that this SAO determines almost the complete variability from the tropopause up to the top of the model. The difference of both variances is shown as dotted-dashed profiles. This shows a maximum in the stratosphere where the QBO is present in CL90, a secondary maximum near $0.1 \mathrm{hPa}$, and a minimum at $1 \mathrm{hPa}$ where the $\mathrm{SAO}$ is strongest.
In summary, the representation of the stratopause SAO and of zonal wind variability in the tropical mesosphere of MAECHAM5 can only be modeled realistically if the QBO is present as a consequence of the improved wave-mean-flow interaction. These results suggest that the atmospheric SAO behavior cannot be correctly simulated in a GCM that does not have a QBO.

\section{Sensitivity of the simulated QBO to resolution and forcing}

Modeling the QBO in a GCM relies on a number of factors. A series of sensitivity experiments (Table 1) has been carried out with the MAECHAM5 GCM to understand better the sensitivity of the simulated QBO to the model setup, and zonal wind composites analogous to that of the CL90 experiment shown in Fig. 5b are discussed below.

\section{a. Vertical resolution}

Analogous to the experiment CL90, two experiments, CL67 and CL52, have been carried out for the same horizontal resolution but with reduced vertical resolutions of 67 and 52 layers, respectively, from the surface to $0.01 \mathrm{hPa}$. These grids have similar characteristics as the 90-layer grid (Fig. 1b) except for the reduced stratospheric target resolutions of 1 and $1.4 \mathrm{~km}$, respectively. The reduction in the vertical resolution degrades the ability of the GCM to represent vertically propagating equatorial waves and to model the interaction of the waves with the mean flow so that changes in the resulting zonal winds are expected.

CL67 still simulates the QBO, though with larger biases than in CL90 (Fig. 13a). Westerlies decrease strongly in amplitude below $20 \mathrm{hPa}$, where the QBO driving relies mostly on resolved waves, and the westerly phase stops already at a higher level near $50 \mathrm{hPa}$. This is an immediate consequence of the degraded simulation of vertically propagating waves. At the same time, westerlies are stronger in the upper stratosphere above $20 \mathrm{hPa}$, where gravity wave drag is important. This is an indirect consequence due to the reduced interaction of the resolved flow in the lower stratosphere, comprising the jets as well as the resolved waves, with the parameterized gravity wave spectrum. As a result, gravity wave drag is redistributed from the lower stratosphere to the upper stratosphere. The increased forcing in the upper stratosphere does not only lead to stronger westerly amplitudes than in CL90, but also explains the shorter period of 21 months. Note also that the westerly jet decreases considerably in amplitude while propagat- 
(a) CL67: W composite in Ur $(\mathrm{m} / \mathrm{s})$ at Eq.

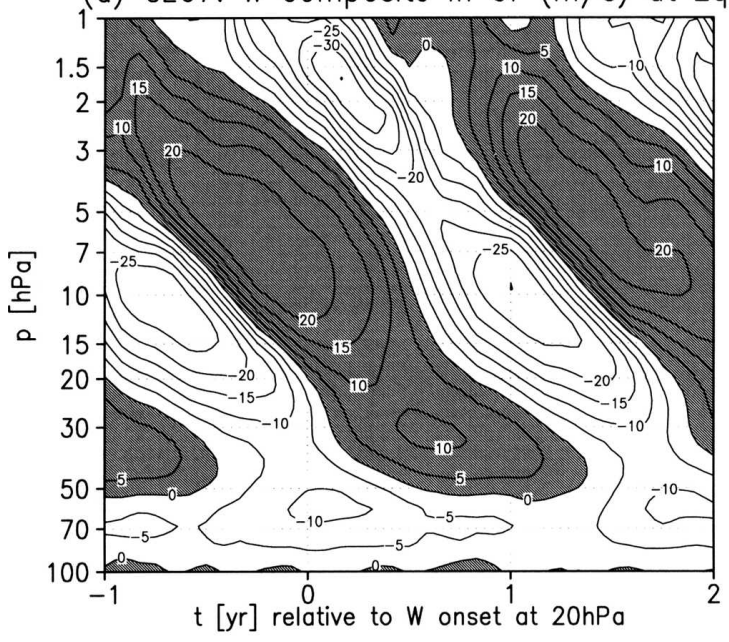

(c) CT31: W composite in Ur $(\mathrm{m} / \mathrm{s})$ at Eq.

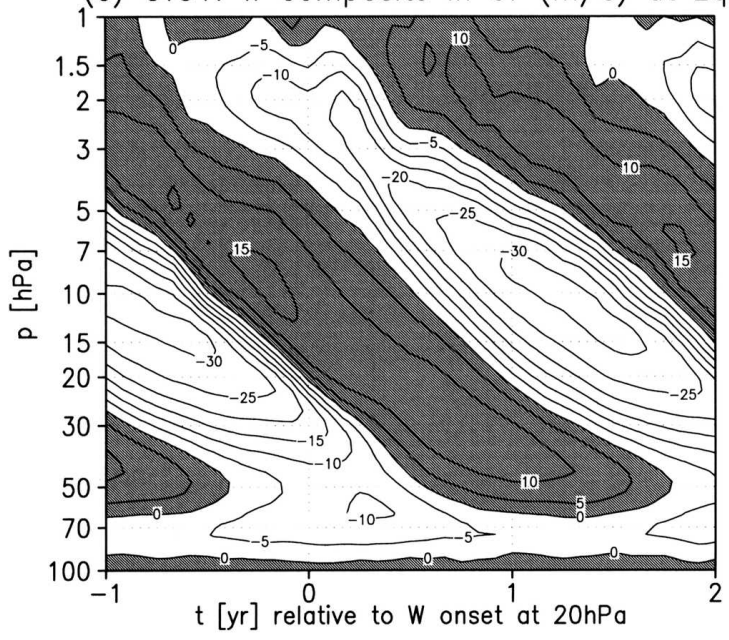

(e) CM10: W composite in $\mathrm{Ur}(\mathrm{m} / \mathrm{s})$ at Eq.

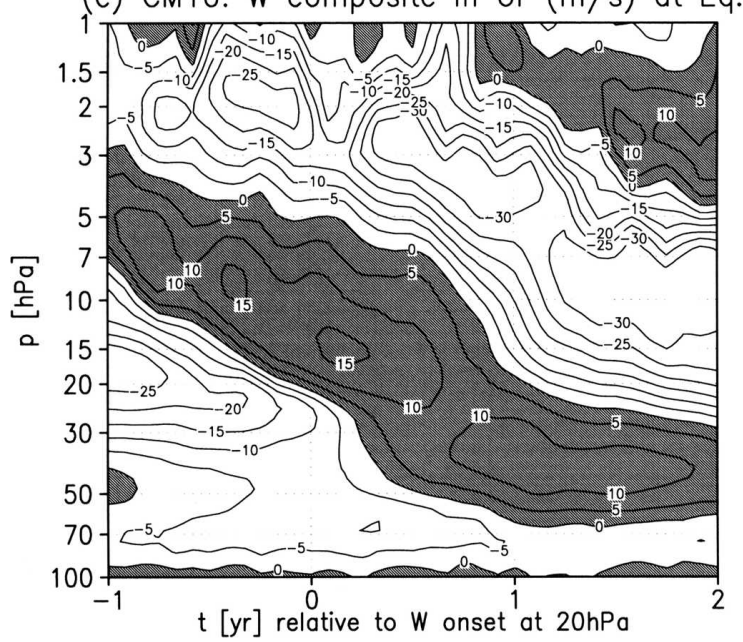

(b) CL52: W composite in Ur $(\mathrm{m} / \mathrm{s})$ at Eq.

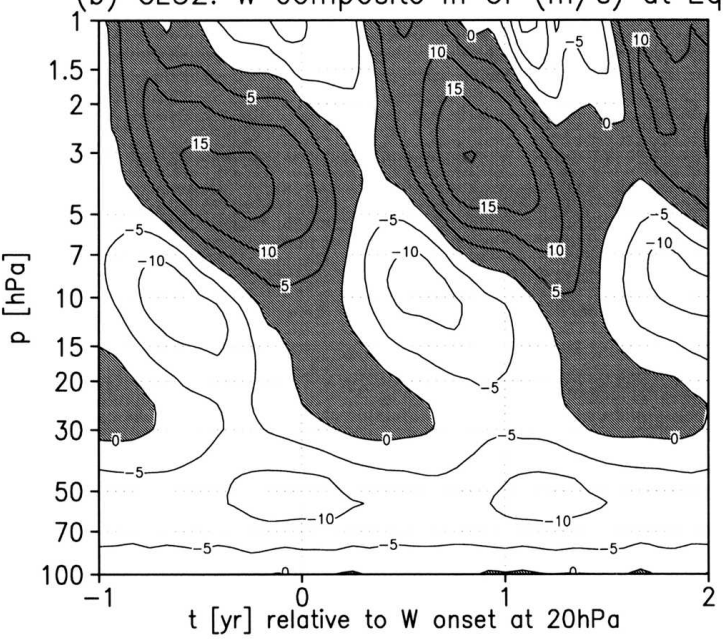

(d) CT63: W composite in Ur $(\mathrm{m} / \mathrm{s})$ at Eq.

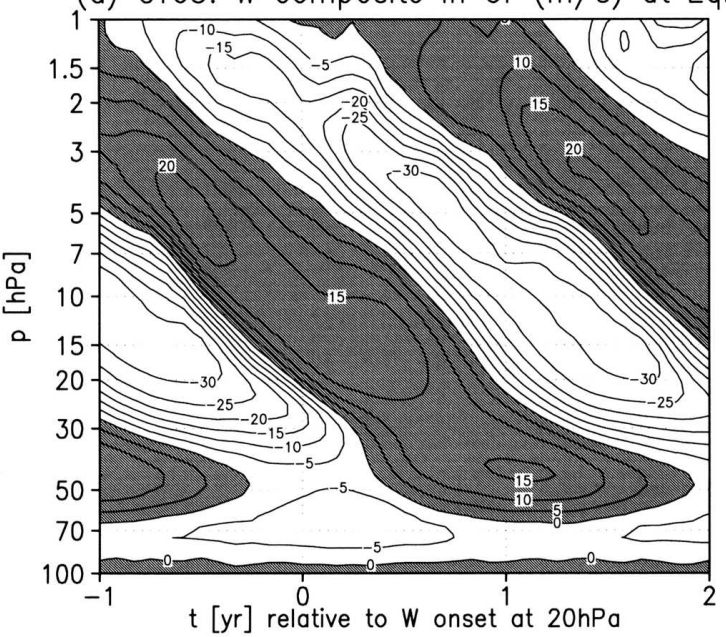

(f) CP10: W composite in Ur $(\mathrm{m} / \mathrm{s})$ at Eq.

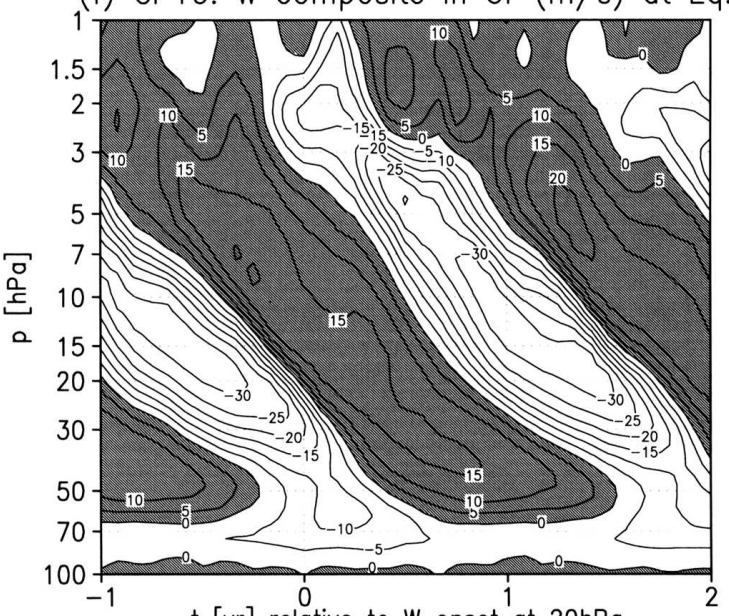

$t$ [yr] relative to $W$ onset at $20 \mathrm{hPa}$

FIG. 13. Composites of westerly phases in $U_{r}$ in sensitivity experiments; see also Table 1. (a) The 67-layer vertical grid, (b) 52-layer vertical grid, (c) T31 horizontal truncation, (d) T63 horizontal truncation, (e) 10\% reduction in rms wind, and (f) $10 \%$ increase in rms wind. Shading indicates westerlies, the contour interval is $5 \mathrm{~m} \mathrm{~s}^{-1}$, and time is shown in units of years. 
ing from the upper stratosphere to the lower stratosphere.

If the resolution is reduced further, as in CL52, then the QBO no longer exists in the full zonal wind field $U$, although the anomaly field $U_{r}$ still contains an oscillation (Fig. 13b). The westerlies and easterlies at $10 \mathrm{hPa}$ are weaker than 5 and $-15 \mathrm{~m} \mathrm{~s}^{-1}$, respectively. Note also that the easterly wind band above the tropopause increases in depth from CL90 (Fig. 5b) to CL67 and CL52. Based on these experiments the vertical resolution needs to be better than $1 \mathrm{~km}$ up to $3 \mathrm{hPa}$.

\section{b. Horizontal resolution}

Horizontal resolution changes imply a change in the resolved spectrum entering the QBO domain. The broader the resolved spectrum is, the stronger the potential wave-mean-flow interaction that may contribute to the QBO forcing. However, it must be noted that at any truncation the wavenumbers close to the truncation limit are subject to the imposed horizontal diffusion operator, which is implemented in ECHAM5 as a $10^{\text {th }}$ order nabla operator so that only a few wavenumbers are significantly affected. Complications must arise if the resolution is increased to scales, which are also part of the assumed continuous source spectrum of the gravity wave drag parameterization. For this reason, only minor horizontal resolution changes of T31 and T63 are considered here. CT31 and CT63 simulate QBOs similar to CL90 with minor differences (Fig. 13c,d). The westerlies in CT31 are slightly weaker, as expected from the stronger truncation of the resolved spectrum, and the termination of the westerly jet occurs a bit earlier than in CL90. In CT63, the QBO westerlies are stronger than in CL90. In the upper stratosphere, the westerlies are now exceeding $20 \mathrm{~m} \mathrm{~s}^{-1}$, indicative of too strong wave-mean-flow interaction. This excess is apparent in the upper stratosphere, which is strongly forced by the parameterized gravity drag, suggesting that already at T63 the gravity wave source spectrum could be slightly reduced due to the higher resolution.

\section{c. Modifications of gravity wave source strength}

The potential wave-mean-low interaction in the QBO domain depends on the excitation intensity of equatorial waves by tropical weather. In the GCMs, this direct relationship exists for the resolved spectrum, but not for the unresolved gravity waves. Gravity wave sources are prescribed in MAECHAM5 as a global constant rms wind at a specified launch level. The default values used in MAECHAM5 are $v_{\mathrm{rms}}=1 \mathrm{~m} \mathrm{~s}^{-1}$ at level 7 from the surface or about $600 \mathrm{hPa}$, as discussed in Charron and Manzini (2002). Using this specification the gravity wave driving contributes to the $\mathrm{QBO}$, as demonstrated for the experiment CL90. Two additional sensitivity experiments CM10 and CP10 were performed, which include a $10 \%$ reduction and a $10 \%$ increase, respectively, of the prescribed rms wind (Figs. 13e,f). The experiment CM10 still generates an equatorial oscillation, though with a strongly increased period of 50 months. The westerly jet amplitude is reduced in the upper stratosphere, though not in the lower stratosphere, where resolved wave forcing is more important. The termination of the westerly phase is delayed since the easterly jet downward propagation is slower. In CP10, the QBO period is reduced to 21 months and the westerly jets are stronger than in CL90.

The sensitivity experiments confirm the expected relationship of resolution in the vertical and horizontal and of wave source strength to the strength of the simulated westerly jet. In addition it is found that the vertical distribution of the resolved and parameterized forcing is important to understanding the resulting QBO periods summarized in Table 1. Stronger resolved waves cause more efficient deposition of parameterized gravity wave drag at lower levels because of the generally stronger shears and wind amplitudes of the resolved circulation. The vertical distribution of the gravity wave forcing of the QBO, at given source strength, therefore depends on the resolved waves. The average period depends on the descent rate of the westerly phase in the upper and middle stratosphere, the total depth of the QBO, and the residence time of the westerly jet in the lower stratosphere. If the gravity wave drag occurs too strongly in the middle and upper stratosphere, for example, because of weak resolved waves in the lower stratosphere, the descent rate would be faster and the QBO depth shallower, such that a too-short QBO period can occur even if the total wave forcing is insufficient (CL90 $\rightarrow$ CL67). The residence time of the westerly jet in the lower stratosphere depends primarily on the resolved waves. Too weak resolved wave forcing cannot propagate the westerly phase deep and long enough. Too small resolved wave forcing therefore leads to too short periods, provided that the downwardpropagating westerly and easterly jets are still induced in the upper stratosphere (CL90 $\rightarrow$ CT31). A too-long QBO period can occur if the descent rate in the upper and middle stratosphere is reduced because of weak gravity wave drag, if the resolved wave forcing is strong enough to propagate the jets to the lower stratosphere (CL90 $\rightarrow$ CM10). Finally, it is found that stronger wave forcing causes shorter periods (CM10 $\rightarrow$ CL90 $\rightarrow$ CP10 or CL90 $\rightarrow$ CT63). Too short QBO periods in GCMs therefore can result from too strong (CL90 $\rightarrow$ CT63) or too weak wave forcing (CL90 $\rightarrow$ CT31). 


\section{Conclusions}

The QBO is a dominant mode of variability in the tropical stratosphere that eventually must be simulated in general circulation models and chemistry climate models that include the stratosphere. This work presents the QBO simulated in the MAECHAM5 GCM at horizontal truncation $\mathrm{T} 42$ and a vertical resolution of ca. $700 \mathrm{~m}$ in the stratosphere. The simulated QBO agrees well with that in ERA-40 in many aspects. The average period is 29 months and westerly and easterly jets have amplitudes of 15 and $-30 \mathrm{~m} \mathrm{~s}^{-1}$, respectively. Biases are identified below $50 \mathrm{hPa}$, where the easterly jet is too weak. Generally, the simulated QBO dissipates too fast below $70 \mathrm{hPa}$. The forcing of the $\mathrm{QBO}$ depends on the resolved and parameterized wavemean-flow interaction, both occurring at similar peak values, as found before in Giorgetta et al. (2002). Resolved wave-mean-flow interaction dominates in the lower stratosphere whereas parameterized gravity wave drag is efficient mostly above $20 \mathrm{hPa}$. The westerly phase propagation, which propagates without loss of amplitude to the lower stratosphere, depends more strongly on the resolved than on parameterized scales. The easterly phase, which decreases strongly in amplitude below $20 \mathrm{hPa}$, depends mostly on the parameterized gravity wave drag. These systematic differences between the phases and their forcing supports the hypothesis that the large-scale resolved waves play a dominant role in the forcing of the QBO westerly phase, while the gravity waves are essential for the easterly phase. Advective tendencies are of the same amplitude as the wave-related tendencies but have different effects on the westerly and easterly phases. Westerly phases are squeezed toward the equator, and the downward propagation of the leading shear zone is strongly reinforced. Easterly phases are broadened, and the downward propagation is strongly opposed by advection.

The QBO is found to be important for the simulation of the climate and variability in the tropical middle atmosphere. This is demonstrated for the annual mean tropical upwelling and the atmospheric tape recorder, which are quantitatively improved in the simulation that includes the QBO compared to an experiment without a QBO. The SAO is well represented in the experiment including the QBO, but strongly biased in structure and amplitude in an experiment without QBO. Modulation and filtering of the equatorial wave spectrum by the QBO is important for the simulation of the SAO. Generally it is found that the variability in the zonal wind at the stratopause and higher cannot be simulated properly without simulating the QBO. QBO and SAO must be considered together. Positive effects of the QBO are expected for the simulation of the middle-atmosphere composition in chemistry climate models where the QBO is often missing.

Sensitivity tests have shown that robust and realistic simulations of the QBO in MAECHAM5 require a vertical resolution better than $1 \mathrm{~km}$. Moderate changes of the horizontal resolution cause small changes in the strength of the QBO. In general, it is found that higher resolution leads to stronger westerly phases. The period of the QBO depends not only on the strength of both the resolved and parameterized wave forcing, but also on their vertical distribution. Too short QBO periods can occur also for too weak wave forcing.

Issues that are not yet resolved in this work are the reasons for the identified bias of the easterly phase in the lower stratosphere and the general easterly bias above the tropopause. Probably this indicates shortcomings in the representation of resolved waves or in the specification of the prescribed gravity wave spectrum. In addition the variability of the wave sources can be underestimated in the experiments presented here for at least two reasons: SSTs are prescribed based on climatological monthly means so that neither intraseasonal nor interannual variability is contained in the boundary conditions, and gravity wave emission is not yet coupled to the actual sources, such as cumulus convection and weather disturbances. These issues will be addressed in future works.

Acknowledgments. Part of this work has been funded by BMBF in AFO2000 and DEKLIM. The simulations have been carried out at the German Climate Computing Center (DKRZ). We thank both reviewers for their constructive suggestions.

\section{REFERENCES}

Andrews, D. G., J. R. Holton, and C. B. Leovy, 1987: Middle Atmosphere Dynamics. Academic Press, 489 pp.

Baldwin, M. P., and L. J. Gray, 2005: Tropical stratospheric zonal winds in ECMWF ERA-40 reanalysis, rocketsonde data, and rawinsonde data. Geophys. Res. Lett., 32, L09806, doi:10.1029/2004GL022328.

- and Coauthors, 2001: The quasi-biennial oscillation. Rev. Geophys., 39, 179-229.

Belmont, A. D., D. G. Dartt, and G. D. Nastrom, 1975: Variations of stratospheric zonal winds, 20-65 km, 1961-1971. J. Appl. Meteor., 14, 585-602.

Bengtsson, L., K. I. Hodges, and S. Hagemann, 2004: Sensitivity of the ERA-40 reanalysis to the observing system: Determination of the global atmospheric circulation from reduced observations. Tellus, 56A, 456-471.

Burrage, M. D., R. A. Vincent, H. G. Mayr, W. R. Skinner, N. F. Arnold, and P. B. Hays, 1996: Long term variability in the 
equatorial mesosphere and lower thermosphere zonal winds. J. Geophys. Res., 101, 12 847-12 854.

Charron, M., and E. Manzini, 2002: Gravity waves from fronts: Parameterization and middle atmosphere response in a general circulation model. J. Atmos. Sci., 59, 923-941.

Delisi, D. P., and T. J. Dunkerton, 1988: Equatorial semiannual oscillation in zonally averaged temperature observed by the Nimbus 7 SAMS and LIMS. J. Geophys. Res., 93, 3899-3904.

Dunkerton, T. J., 1997: The role of gravity waves in the quasibiennial oscillation. J. Geophys. Res., 102, 26 053-26076.

— , and D. P. Delisi, 1997: Interaction of the quasi-biennial oscillation and stratopause semiannual oscillation. J. Geophys. Res., 102, 26 107-26 116.

Giorgetta, M. A., E. Manzini, and E. Roeckner, 2002: Forcing of the quasi-biennial oscillation from a broad spectrum of atmospheric waves. Geophys. Res. Lett., 29, 1245, doi:10.1029/ 2002 GL014756.

Hamilton, K., 1984: Mean wind evolution through the quasibiennial cycle of the tropical lower stratosphere. J. Atmos. Sci., 41, 2113-2125.

- R. J. Wilson, and R. S. Hemler, 1999: Middle atmosphere simulations with high vertical and horizontal resolution versions of a GCM: Improvements in the cold pole bias and generation of a QBO-like oscillation in the Tropics. J. Atmos. Sci., 56, 3829-3856.

Hines, C. O., 1997: Doppler-spread parameterization of gravity wave momentum deposition in the middle atmosphere. Part 2: Broad and quasi-monochromatic spectra, and implementation. J. Atmos. Sol. Terr. Phys., 59, 387-400.

Holton, J. R., and R. S. Lindzen, 1972: An updated theory for the quasi-biennial cycle of the tropical stratosphere. J. Atmos. Sci., 29, 1076-1080.

Horinouchi, T., and Coauthors, 2003: Tropical cumulus convection and upward-propagating waves in middle-atmospheric GCMs. J. Atmos. Sci., 60, 2765-2782.

Labitzke K., and Coauthors, 2002: The Berlin Stratospheric Data Series. Meteorological Institute, Free University of Berlin, CD-ROM.

Lindzen, R. S., and J. R. Holton, 1968: A theory of the quasibiennial oscillation. J. Atmos. Sci., 25, 1095-1107.

Manzini, E., M. A. Giorgetta, M. Esch, L. Kornblueh, and E. Roeckner, 2006: The influence of sea surface temperatures on the northern winter stratosphere: Ensemble simulations with the MAECHAM5 model. J. Climate, 19, 3863-3881.

Mote, P. W., and Coauthors, 1996: An atmospheric tape recorder: The imprint of tropical tropopause temperatures on stratospheric water vapor. J. Geophys. Res., 101, 3989-4006.

Naujokat, B., 1986: An update of the observed quasi-biennial oscillation of the stratospheric winds over the tropics. J. Atmos. Sci., 43, 1873-1877.
Pawson, S., and M. Fiorino, 1998: A comparison of reanalyses in the tropical stratosphere. Part 2: The quasi-biennial oscillation. Climate Dyn., 14, 645-658.

Randel, W. J., F. Wu, R. Swinbank, J. Nash, and A. O'Neill, 1999: Global QBO circulation derived from UKMO stratospheric analyses. J. Atmos. Sci., 56, 457-474.

—- and Coauthors, 2004: The SPARC intercomparison of middle-atmosphere climatologies. J. Climate, 17, 986-1003.

Ricciardulli, L., and R. R. Garcia, 2000: The excitation of equatorial waves by deep convection in the NCAR Community Climate Model (CCM3). J. Atmos. Sci., 57, 3461-3487.

Roeckner, E., and Coauthors, 2003: The atmospheric general circulation model ECHAM5. Part I. Model description. Tech. Rep. 349, MPI for Meteorology, Hamburg, Germany, 127 pp.

_ , and Coauthors, 2006: Sensitivity of simulated climate to horizontal and vertical resolution in the ECHAM5 atmosphere model. J. Climate, 19, 3771-3791.

Rosenlof, K. H., A. F. Tuck, K. K. Kelly, J. M. Russell III, and M. P. McCormick, 1997: Hemispheric asymmetries in water vapor and inferences about transport in the lower stratosphere. J. Geophys. Res., 102, 13 213-13 234.

Scaife, A., N. Butchart, C. D. Warner, D. Stainforth, and W. Norton, 2000: Realistic quasi-biennial oscillations in a simulation of the global climate. Geophys. Res. Lett., 27, 34813484.

Scinocca, J. F., and N. A. McFarlane, 2004: The variability of modeled tropical precipitation. J. Atmos. Sci., 61, 1993-2015.

Simmons, A. J., and J. K. Gibson, 2000: The ERA-40 project plan. ERA-40 Project Report Series 1, ECMWF, Reading, United Kingdom, 63 pp.

Steil, B., C. Brühl, E. Manzini, P. J. Crutzen, J. Lelieveld, P. J. Rasch, E. Roeckner, and K. K. Krüger, 2003: A new interactive chemistry-climate model: 1 . Present-day climatology and interannual variability of the middle atmosphere using the model and 9 years of HALOE/UARS data. J. Geophys. Res., 108, 4290, doi:10.1029/2002JD002971.

Takahashi, M., 1996: Simulation of the stratospheric quasibiennial oscillation using a general circulation model. Geophys. Res. Lett., 23, 661-664.

_ 1999: Simulation of the stratospheric quasi-biennial oscillation in a general circulation model. Geophys. Res. Lett., 26, 1307-1310.

_ and B. A. Boville, 1992: A three-dimensional simulation of the equatorial quasi-biennial oscillation. J. Atmos. Sci., 49, 1020-1035.

Uppala, S., and Coauthors, 2004: ERA-40: ECMWF 45-year reanalysis of the global atmosphere and surface conditions 1957-2002. ECMWF Newsletter, No. 101, ECMWF, Reading, United Kingdom, 2-21. 